Article

\title{
Studies on a Hybrid Full-Bridge/Half-Bridge Bidirectional CLTC Multi-Resonant DC-DC Converter with a Digital Synchronous Rectification Strategy
}

\author{
Shu-huai Zhang ${ }^{1}$, Yi-feng Wang ${ }^{1, * \mathbb{B}}$, Bo Chen ${ }^{1}$, Fu-qiang Han ${ }^{1}$ and Qing-cui Wang ${ }^{2}$ \\ 1 Key Laboratory of Smart Grid of Ministry of Education, Tianjin University, Tianjin 300072, China; \\ zhangshuhuai@tju.edu.cn (S.-h.Z.); cb92614@126.com (B.C.); fqhanyz@foxmail.com (F.-q.H.) \\ 2 Tianjin Research Institute of Electric Science Co., Ltd. (TRIED), Tianjin 300300, China; \\ wangqingcui66@163.com \\ * Correspondence: wayif@tju.edu.cn; Tel.: +86-185-2206-2559
}

Received: 18 December 2017; Accepted: 15 January 2018; Published: 18 January 2018

\begin{abstract}
This study presents a new bidirectional multi-resonant DC-DC converter, which is named CLTC. The converter adds an auxiliary transformer and an extra resonant capacitor based on a LLC resonant DC-DC converter, achieving zero-voltage switching (ZVS) for the input inverting switches and zero-current switching (ZCS) for the output rectifiers in all load range. The converter also has a wide gain range in two directions. When the load is light, a half-bridge configuration is adopted instead of a full-bridge configuration to solve the problem of voltage regulation. By this method, the voltage gain becomes monotonous and controllable. Besides, the digital synchronous rectification strategy is proposed in forward mode without adding any auxiliary circuit. The conduction time of synchronous rectifiers equals the estimation value of body diodes' conduction time with the lightest load. Power loss analysis is also conducted in different situations. Finally, the theoretical analysis is validated by a $5 \mathrm{~kW}$ prototype.
\end{abstract}

Keywords: bidirectional CLTC resonant DC-DC converter; light load; synchronous rectification strategy; power loss analysis

\section{Introduction}

With advantage of ZVS + ZCS, the bidirectional resonant DC-DC converter (BRDC) is gaining more attention in DC distribution system or DC microgrid applications [1-8]. All the power switching devices, including metal oxide semiconductor field effect transistor (MOSFET) switches and diodes have the desirable soft-switching features, and the switching loss is greatly decreased. In addition, the electromagnetic interference (EMI) is also restricted. As a result, BRDCs are characterized by high efficiency, high power density and low EMI, and are applicable to high frequency applications $[9,10]$. Among all the BRDCs, the bidirectional series resonant converter (BSRC) is a candidate topology [11-16]. All the switches of a BSRC work in either ZVS or ZCS for a wide variation of voltage gains with phase-shift control [13]. A novel control scheme was developed for BSRC in discontinuous mode [14]. With the accumulation of energy packets to raise output voltage, it is possible to have a gain greater than one. A novel method for analyzing the frequency response is also presented based on a mixture of the Fourier and the average state-space methods [15]. The analysis method provides enough information to properly control the BSRC. A BSRC using a continuous current mode was proposed in [16]. Experimental results from a $6 \mathrm{~kW}$ prototype validated the theoretical analysis, and higher efficiency is obtained compared to the phase-shift DAB in a wide power range. However, the efficiency 
is not ideal for the whole frequency range. A bidirectional LLC resonant DC-DC converter is also a good option. A bidirectional three-level LLC resonant converter has a very wide voltage gain range with PWAM control [17]. It overcomes the limitation of voltage gain in LLC resonant converters. A bidirectional LLC resonant converter with automatic forward and backward mode transition is proposed in [18]. An auxiliary inductor is added to raise the voltage gain in backward operation. Based on LLC, a symmetrical bidirectional CLLC resonant converter was recently proposed [19-21]. The voltage gain in backward operation is the same as that in forward operation. However, with the growth of output power and voltage conversion ratio, the resonant inductance is small and the resonant capacitance is big. These parameters are hard to design.

Besides, the regulation capability of a resonant DC-DC converter is weak under light load conditions. Due to parasitic parameters in the resonant tank, the output voltage goes up as the switching frequency increases, and an upturn drifting occurs in the voltage gain curve [22]. This phenomenon causes trouble for voltage regulation under light load conditions. To solve this problem, many researchers have changed the control method for light load conditions [23-28]. Burst mode is used in [23,24], but the ripple of the output voltage is large and the dynamic response is slow. The phase-shift and PWM control methods are effective in [25-28], but the control scheme is complex due to the additional control elements. The changes are also conducted with the topology of resonant DC-DC converter. Adding an additional output capacitor to switches can reduce current ripple and decrease powering transmitted between two sides of transformer [29], but the ZVS range this time is narrow. An additional capacitor is paralleled with the resonant inductor to improve the gain characteristics in [30]. ZVS is acquired under entire load condition, and efficiency is improved with less turn-off loss, but the design of the transformer and additional capacitor is complex due to resonance between leakage inductor and the additional capacitor.

The synchronous rectification (SR) strategy for resonant converters is also important toward achieving working efficiency [31-34]. A novel driving scheme with a compensation network for synchronous rectifiers is used in LLC resonant converters. The conduction loss and switching loss are also reduced considerably [35]. A hybrid driving scheme for full-bridge SR is proposed in [36]. It uses one transformer auxiliary winding to drive two high-side SR switches and a simple current transformer (CT) to drive two low-side SR switches. The proposed method operates well under DCM and CCM conditions. A novel SR control strategy is developed, through accurately tracking the target switching moments in [37]. However, the strategies above are complex in application and they are not verified in BRDCs. A new synchronous rectification strategy, which is simpler and compatible to bidirectional power flow, needs to be developed.

In this study, a new bidirectional CLTC multi-resonant DC-DC converter is proposed. As Figure 1 shows, the converter is composed of a high-voltage side (HVS) full-bridge, low-voltage side (LVS) full-bridge and a multi-resonant tank. An auxiliary transformer $T_{2}$ and an extra resonant capacitor $C_{\mathrm{r} 2}$ are added on bidirectional LLC resonant DC-DC converter, so the converter is named by CLTC. The gain range in two directions is broadened with the added devices. ZVS for the input inverting switches and ZCS for the output rectifiers are realized in all load range. $U_{\mathrm{H}}$ represents HVS DC voltage, while $U_{\mathrm{L}}$ represents LVS DC voltage. Power flows in both forward and backward mode are modulated with pulse frequency modulation (PFM). In forward mode, $S_{1} \& S_{4}$ and $S_{2} \& S_{3}$ run with $50 \%$ duty cycle, the rectifier switches $S_{6} \& S_{7}$ and $S_{5} \& S_{8}$ are driven by the SR signals. In backward mode, $S_{6} \&$ $\mathrm{S}_{7}$ and $\mathrm{S}_{5} \& \mathrm{~S}_{8}$ run at $50 \%$ duty cycle, $\mathrm{S}_{1} \& \mathrm{~S}_{4}$ and $\mathrm{S}_{2} \& \mathrm{~S}_{3}$ don't work, diodes on HVS realize SR.

This paper is organized as follows: the operation principles and characteristic descriptions of the proposed converter are discussed in Section 2. Hybrid full-bridge/half-bridge configuration is used to improve the light load regulation capability in Section 3. Stresses of power devices, load and working frequency range in half-bridge CLTC are also given to prove the feasibility of the half-bridge configuration. SR strategy based on estimation of the diodes' conduction time is proposed in Section 4 . Power loss distribution and comparison tests are conducted with different loads and LVS DC voltages in Section 5. A $5 \mathrm{~kW}$ prototype is built with HVS voltage of $400 \mathrm{~V}$ and LVS DC voltage of $42-58 \mathrm{~V}$. 
Experimental results are shown to validate the theoretical analysis above in Section 6. Conclusions are drawn in Section 7.

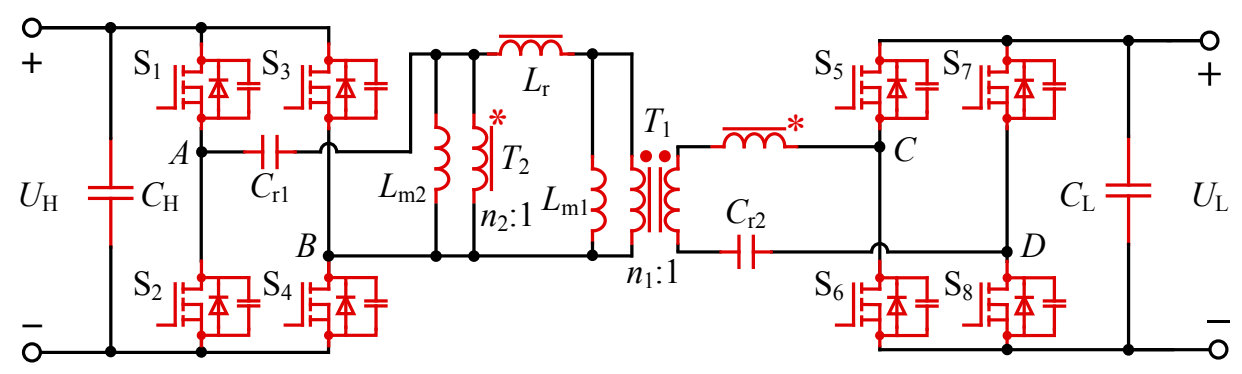

Figure 1. The proposed bidirectional CLTC multi-resonant DC-DC converter.

\section{Operation Principles and Characteristic Description}

In this section, the main operation principles of CLTC multi-resonant converter are given. It is similar to a LLC resonant converter as two stages of resonance exist. The resonant frequency, voltage gain and ZVS characteristic are analyzed, forming research foundations for the following sections.

\subsection{Operation Principles}

Figure 2 shows different states of the CLTC multi-resonant converter. In Figure $2, i_{\mathrm{Lm} 1}$ is excitation current of transformer $T_{1}$ on HVS, $i_{\mathrm{Lm} 1}^{\prime}$ is excitation current of transformer $T_{1}$ on LVS, $i_{\mathrm{Lr}}$ is current of resonant inductor, $i_{\mathrm{Cr} 1}$ and $i_{\mathrm{Cr} 2}$ are currents of resonant capacitors on HVS and LVS, $u_{\mathrm{GS} 14}$ is the driving signal of $S_{1}$ and $S_{4}, u_{G S 23}$ is the driving signal of $S_{2}$ and $S_{3}, u_{G S 58}$ is the driving signal of $S_{5}$ and $S_{8}, u_{\mathrm{GS} 67}$ is the driving signal of $\mathrm{S}_{6}$ and $\mathrm{S}_{7}, u_{\mathrm{DS} 14}$ is the drain-source voltage of $\mathrm{S}_{1}$ and $\mathrm{S}_{4}, u_{\mathrm{DS} 23}$ is the drain-source voltage of $S_{2}$ and $S_{3}, u_{\mathrm{DS} 58}$ is the drain-source voltage of $S_{5}$ and $S_{8}, u_{\mathrm{DS} 67}$ is the drain-source voltage of $S_{6}$ and $S_{7}, i_{D S 14}$ is the drain-source current of $S_{1}$ and $S_{4}, i_{D S 23}$ is the drain-source current of $S_{2}$ and $S_{3}, i_{\text {DS58 }}$ is the drain-source current of $S_{5}$ and $S_{8}, i_{\text {DS67 }}$ is the drain-source current of $\mathrm{S}_{6}$ and $\mathrm{S}_{7}$.

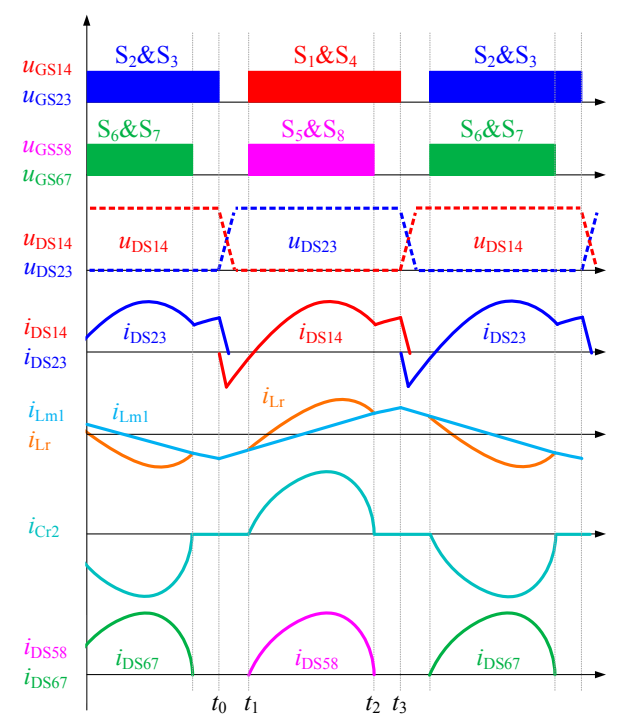

(a)

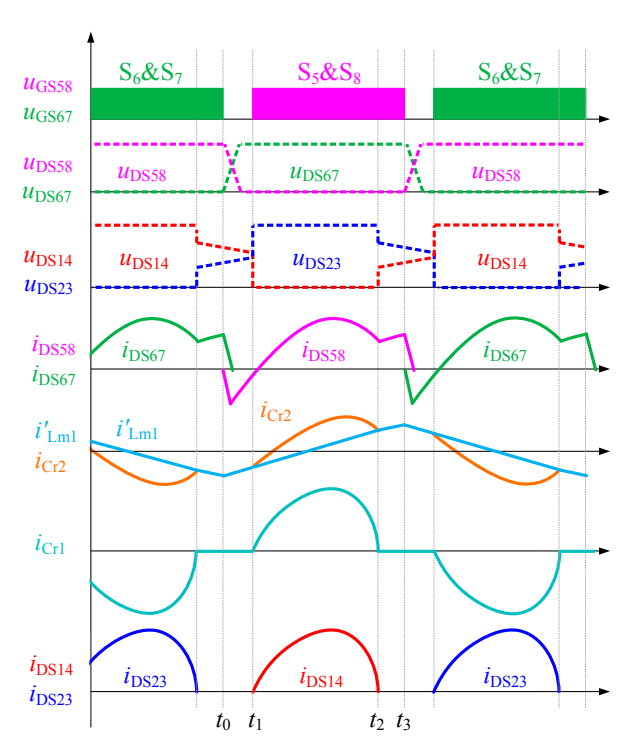

(b)

Figure 2. The current and voltage waveforms of CLTC multi-resonant converter: (a) forward mode; (b) backward mode. 


\subsubsection{Forward Mode}

The equivalent circuits in forward mode are listed in Figure 3. Detailed descriptions and explanations of the operational modes in half period are as follows:

Mode A [ $\left.t_{0}-t_{1}\right]: S_{2}$ and $S_{3}$ have just turned off at $t_{0}$. The HVS current charges the output capacitor of $S_{2}$ and $S_{3}$, and discharges the output capacitor of $S_{1}$ and $S_{4}$. After that, the HVS current passes through the antiparallel diode of $S_{1}$ and $S_{4}$, which makes the switches turn on under the ZVS condition.

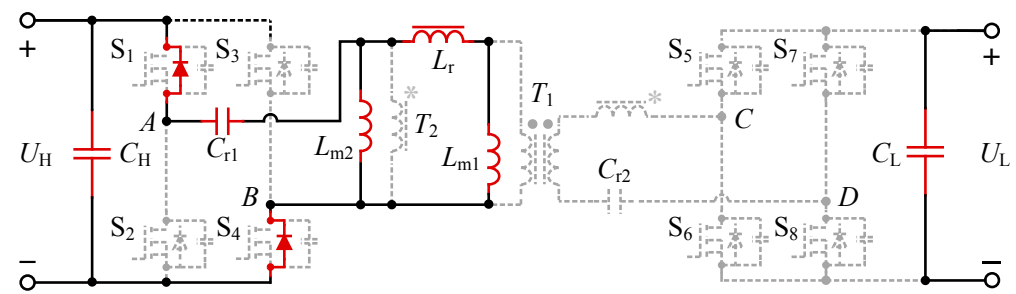

(a)

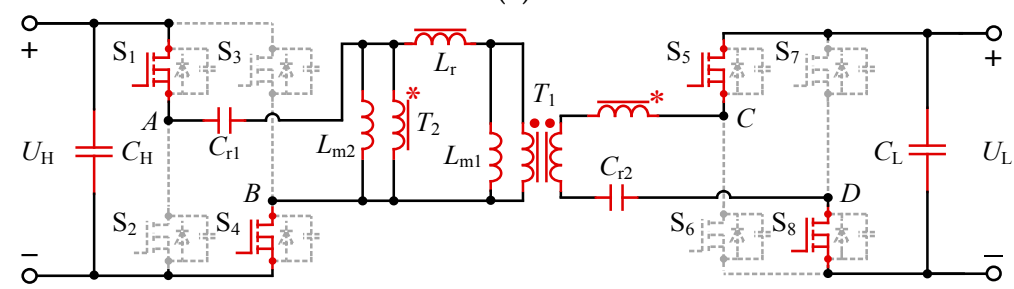

(b)

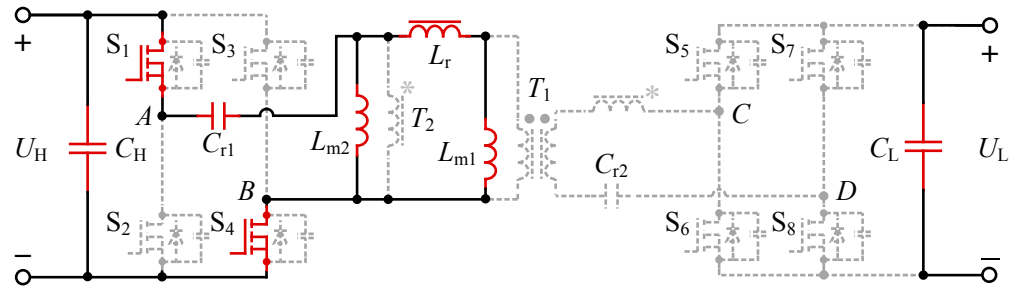

(c)

Figure 3. Equivalent circuits for each stage in forward mode: (a) Mode A; (b) Mode B; (c) Mode C.

Mode B [ $\left.t_{1}-t_{2}\right]$ : At $t_{1}, S_{1}, S_{4}, S_{5}$ and $S_{8}$ turn on and power is transferred from HVS to LVS. The resonant current changes in a sine-wave with main resonant frequency, $f_{\mathrm{r}}$. At $t_{2}, i_{\mathrm{Lr}}$ is equal to $i_{\mathrm{Lm} 1}, i_{\mathrm{Cr} 2}$ and $i_{\mathrm{ds} 58}$ become zero.

Mode $C\left[t_{2}-t_{3}\right]: S_{1}$ and $S_{4}$ are still on in this mode, $S_{5}$ and $S_{8}$ are off in this mode. As $i_{\mathrm{Cr} 2}$ and $i_{\mathrm{ds} 58}$ are zero in $t_{2}, S_{5}$ and $S_{8}$ turn off under ZCS condition. The HVS goes into secondary resonance with the frequency of $f_{\mathrm{r} 2 \mathrm{f}}$. At $t_{3}, \mathrm{~S}_{1}$ and $\mathrm{S}_{4}$ are off and ready to go into dead-time duration.

When working frequency is bigger than main resonant frequency, Mode C and ZCS of LVS power switches disappear like LLC. The turn-off currents increase largely in this situation.

\subsubsection{Backward Mode}

The equivalent circuits in backward mode are listed in Figure $4 . L_{\mathrm{m} 1}^{\prime}$ and $L_{\mathrm{m} 2}^{\prime}$ are the magnetizing inductors on LVS. The modes are similar to those in forward mode. Detail descriptions and explanations of the operational modes in half period are shown as follows:

Mode A [ $\left.t_{0}-t_{1}\right]: S_{6}$ and $S_{7}$ turn off at $t_{0}$. The resonant current on LVS charges the output capacitor of $S_{6}$ and $S_{7}$, and discharges the output capacitor of $S_{5}$ and $S_{8}$. After that, the LVS current passes through the antiparallel diode of $S_{5}$ and $S_{8}$, which makes the switches turn on under the ZVS condition.

Mode $B\left[t_{1}-t_{2}\right]$ : At $t_{1}, S_{5}, S_{8}, D_{1}$ and $D_{4}$ turn on and power is transferred from LVS to HVS. The resonant current on LVS changes in a sine-wave with main resonant frequency. At $t_{2}, i_{\mathrm{Cr} 2}$ is equal to $i_{\mathrm{Lm} 1}^{\prime}, i_{\mathrm{Cr} 1}$ and $i_{\mathrm{ds} 14}$ become zero. 
Mode $C\left[t_{2}-t_{3}\right]: S_{5}$ and $S_{8}$ are still on in this mode, $D_{1}$ and $D_{4}$ are off in this mode. ZCS of $D_{1}$ and $\mathrm{D}_{4}$ is realized as $i_{\mathrm{Cr} 1}$ and $i_{\mathrm{ds} 14}$ become zero at $t_{2}$. The LVS goes into secondary resonance with the frequency of $f_{\mathrm{r} 2 \mathrm{~b}}$. At $t_{3}, S_{1}$ and $S_{4}$ are off and ready to go into dead-time duration.

When working frequency is bigger than main resonant frequency, Mode $\mathrm{C}$ and ZCS of HVS diodes disappear like LLC. The turn-off currents increase largely in this situation.

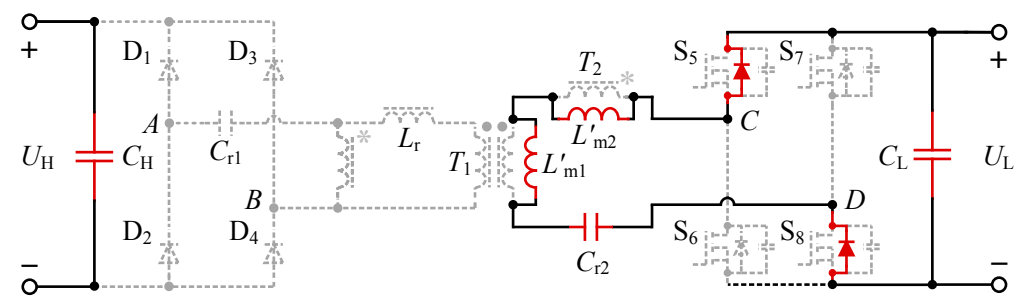

(a)

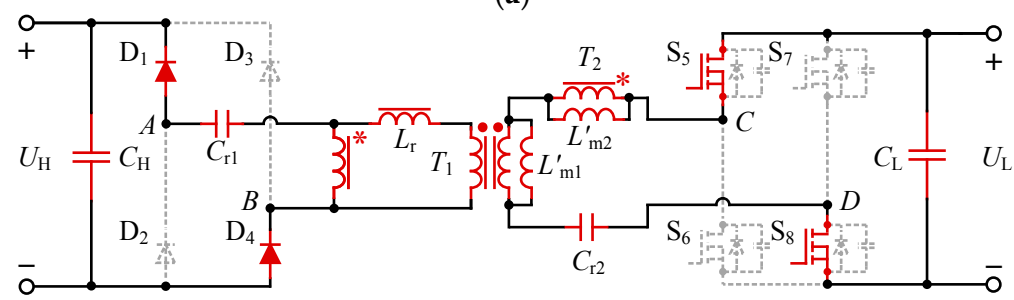

(b)

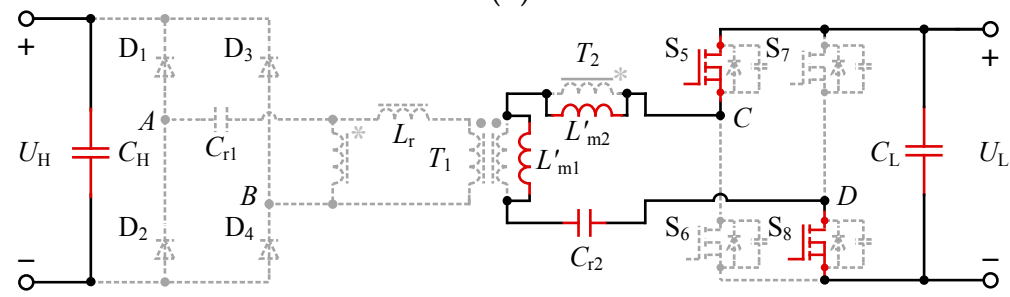

(c)

Figure 4. Equivalent circuits for each stage in backward mode: (a) Mode A; (b) Mode B; (c) Mode C.

\subsection{Characteristic Description}

Main resonant frequency of CLTC converter in two power flows, $f_{\mathrm{r}}$, is:

$$
f_{\mathrm{r}}=\frac{1}{2 \pi} \sqrt{\frac{A}{B}}
$$

where:

$$
\begin{gathered}
A=A_{1}+A_{1}^{2}-A_{2} \\
A_{1}=C_{\mathrm{r} 1} L_{\mathrm{m} 2}\left(L_{\mathrm{m} 1}+L_{\mathrm{r}}\right) n_{1}{ }^{2} n_{2}{ }^{2}+\left(L_{\mathrm{m} 1}+L_{\mathrm{r}}\right) C_{\mathrm{r} 2} L_{\mathrm{m} 2} n^{2}+\left(L_{\mathrm{m} 2}+L_{\mathrm{r}}\right) C_{\mathrm{r} 2} L_{\mathrm{m} 1} n_{2}{ }^{2}+2 C_{\mathrm{r} 2} L_{\mathrm{m} 1} L_{\mathrm{m} 2} n_{1} n_{2} \\
A_{2}=4 C_{\mathrm{r} 1} C_{\mathrm{r} 2} L_{\mathrm{m} 1} L_{\mathrm{m} 2} L_{\mathrm{r}}\left(L_{\mathrm{m} 1}+L_{\mathrm{m} 2}+L_{\mathrm{r}}\right) n_{1}{ }^{2} n_{2}{ }^{4} \\
B=2 C_{\mathrm{r} 1} C_{\mathrm{r} 2} L_{\mathrm{m} 1} L_{\mathrm{m} 2} L_{\mathrm{r}} n_{2}{ }^{2}
\end{gathered}
$$

$f_{\mathrm{r}}$ is obtained when no load is added and imaginary part of AC input impedance of CLTC is zero.

The secondary resonant frequency in forward mode, $f_{\mathrm{r} 2 \mathrm{f}}$, and the secondary resonant frequency in backward mode, $f_{\mathrm{r} 2 \mathrm{~b}}$, are:

$$
\begin{gathered}
f_{\mathrm{r} 2 \mathrm{f}}=\frac{1}{2 \pi} \sqrt{\frac{L_{\mathrm{r}}+L_{\mathrm{m} 1}+L_{\mathrm{m} 2}}{C_{\mathrm{r} 1} L_{\mathrm{m} 2}\left(L_{\mathrm{r}}+L_{\mathrm{m} 1}\right)}} \\
f_{\mathrm{r} 2 \mathrm{~b}}=\frac{1}{2 \pi \sqrt{\left(L_{\mathrm{m} 1}^{\prime}+L_{\mathrm{m} 2}^{\prime}\right) C_{\mathrm{r} 2}}}
\end{gathered}
$$


$f_{\mathrm{r} 2 \mathrm{f}}$ and $f_{\mathrm{r} 2 \mathrm{~b}}$ are obtained with the resonant capacitance and inductance in secondary resonance. The resonant capacitance and inductance are shown in Figures $3 \mathrm{c}$ and $4 \mathrm{c}$.

By use of the fundamental harmonic analysis (FHA) method, Figures 5 a and 6a show 3D voltage gain curves according to load $P_{\mathrm{o}}$ and normalized working frequency $f_{\mathrm{s}} / f_{\mathrm{r}}$. $G_{\mathrm{F}}$ is gain in forward mode and $G_{B}$ is gain in backward mode. As is shown in Figures $5 b$ and $6 b$, when the working frequency is below the main resonant frequency, $G_{F}$ and $G_{B}$ increase at first and decrease subsequently with the growth of working frequency. The peak gains are more than 1 over all the load range and obtained around secondary resonant frequency, $f_{\mathrm{r} 2 \mathrm{f}}$ and $f_{\mathrm{r} 2 \mathrm{~b}}$. At main resonant frequency $f_{\mathrm{r}}$, the gain of the converter is 1 . As is shown in Figures $5 c$ and $6 c$, when working frequency is above main resonant frequency, $G_{\mathrm{F}}$ and $G_{\mathrm{B}}$ decrease with the growth of working frequency. When load is lighter, the voltage gain is higher and the slope of gain curve is sharper. Voltage gain range of CTLC converter is wide enough to adapt applications like battery charger and DC microgrid.

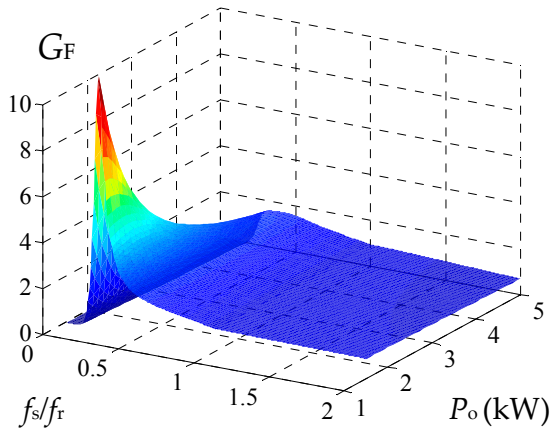

(a)

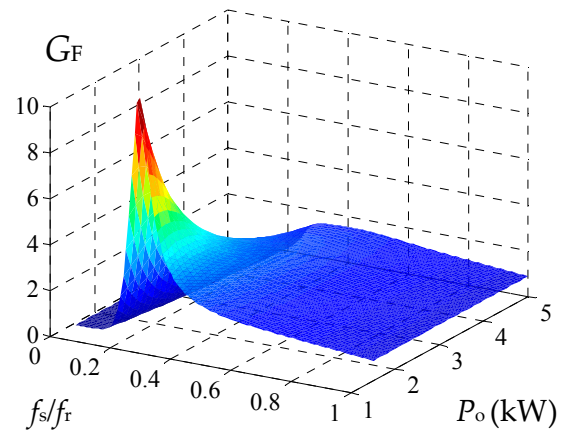

(b)

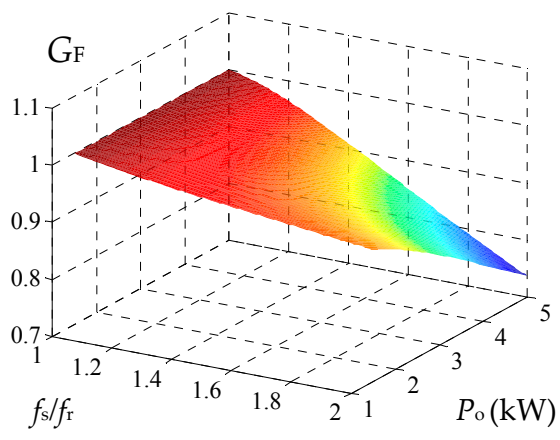

(c)

Figure 5. Voltage gain obtained by FHA model in forward mode: (a) whole frequency range; $(\mathbf{b}) f_{\mathrm{s}}<f_{\mathrm{r}}$; (c) $f_{\mathrm{s}} \geq f_{\mathrm{r}}$.

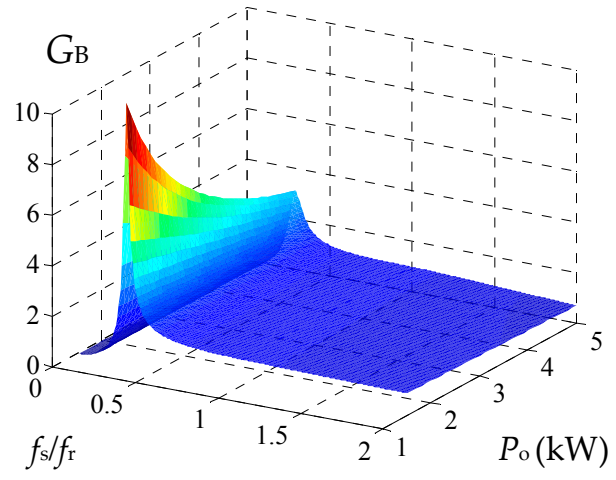

(a)

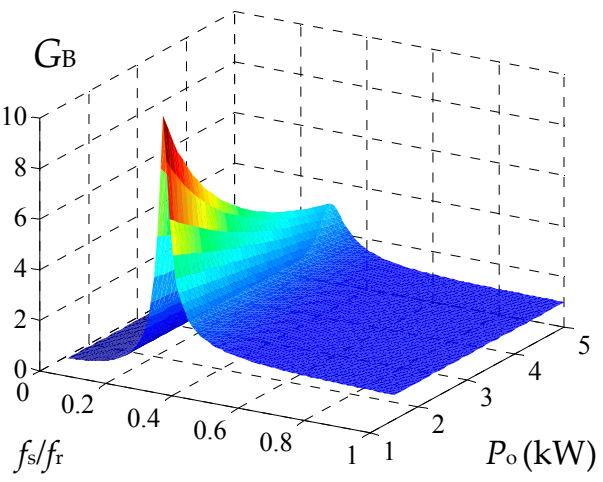

(b)

Figure 6. Cont. 


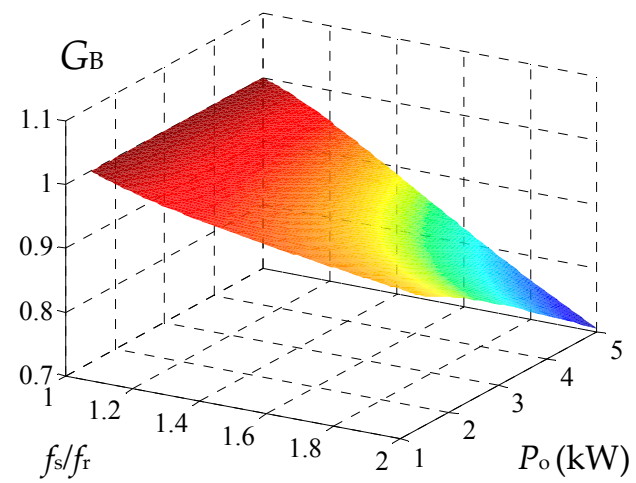

(c)

Figure 6. Voltage gain obtained by FHA model in backward mode: (a) whole frequency range; (b) $f_{\mathrm{s}}<f_{\mathrm{r}}$; (c) $f_{\mathrm{s}} \geq f_{\mathrm{r}}$.

In order to realize ZVS for HVS switches, in forward mode, the dead-time duration $t_{\mathrm{dt} \_\mathrm{F}}$ should satisfy (6) using the ZVS mechanism analyzed by [19]. $C_{\text {oss_H }}$ is the output capacitance of HVS switch:

$$
t_{\mathrm{dt} \_\mathrm{F}} \geq \frac{16 C_{\mathrm{oss}_{\_} \mathrm{H}} L_{\mathrm{m} 2}\left(L_{\mathrm{r}}+L_{\mathrm{m} 1}\right) f_{\mathrm{s}}}{L_{\mathrm{r}}+L_{\mathrm{m} 1}+L_{\mathrm{m} 2}}
$$

Similarly, in backward mode, the dead-time duration $t_{\mathrm{dt} \_\mathrm{B}}$ of LVS switches should satisfy:

$$
t_{\mathrm{dt} \_\mathrm{B}} \geq 16 C_{\text {oss_L }}\left(L_{\mathrm{m} 1}^{\prime}+L_{\mathrm{m} 2}^{\prime}\right) f_{\mathrm{s}}
$$

$\mathrm{C}_{\text {oss_L }}$ is the output capacitance of LVS switch in (7).

The inequations can be easily satisfied with different loads and working frequencies, which is good for efficiency. The $t_{\mathrm{dt} \_\mathrm{F}}$ and $t_{\mathrm{dt} \_\mathrm{B}}$ are set to $200 \mathrm{~ns}$ in experiments.

\section{Hybrid Full-Bridge/Half-Bridge Configuration}

In this section, the reason for the upturn phenomenon is analyzed. A full-bridge configuration is used with a normal load. Half-bridge configurations are used for light load conditions with the advantage of monotonous gain curve and lower frequency. Because the situations in forward and backward mode are similar, the discussion in this section is conducted only in forward mode, and details are not provided for the backward mode.

\subsection{Half-Bridge Configuration at Light Load Condition}

Using the analysis method proposed in [22], it is found that transformer wiring capacitance is the main factor leading to the upturn problem. As is shown in Figure 7a, the ideal gain curve without considering parasitic parameters in forward mode is monotonous with working frequency under light load conditions. However, the voltage gain curve considering transformer wiring capacitance and experimental gain curve has upturns. As the experiment gain curve is not monotonous, the gain cannot be regulated well with PFM. For example, the voltage gain of 1.02 in Figure 7a is obtained with four different working frequencies. When PFM is adopted to control LVS voltage, the working frequency may be around $1.4 f_{\mathrm{r}}$ instead of $0.8 f_{\mathrm{r}}$, and fluctuates quickly as the gain curve is not monotonous.

To overcome the above problem, a half-bridge configuration is introduced in this paper to regulate the required output voltage. In forward mode, the full-bridge in HVS is transformed into a half-bridge by turning off $Q_{3}$ and turning on $Q_{4}$ incessantly. The voltage gain is reduced by half, with the same load and resonant parameters. Thus, when the voltage gain needed is below 1 under light load conditions, a half-bridge configuration is adopted and the required gain is obtained with lower working frequency. 
In Figure $7 \mathrm{~b}$, when the working frequency is around $0.35 f_{\mathrm{r}}$, twice the required gain is acquired in full-bridge configuration. Thus, a gain of 1.02 is acquired in half-bridge configuration with the same working frequency and load. Also, the gain of 1.02 is controllable in half-bridge mode, because the working frequency decreases largely, away from the region where the gain is not monotonous.

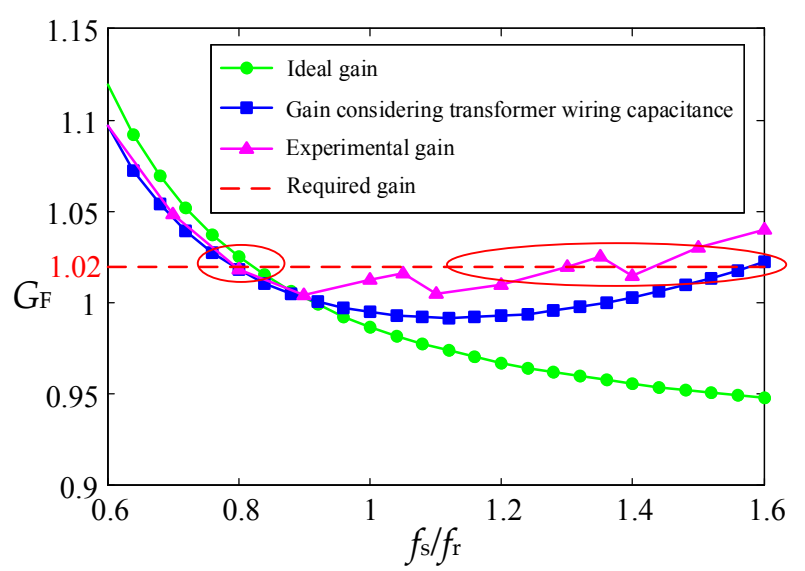

(a)

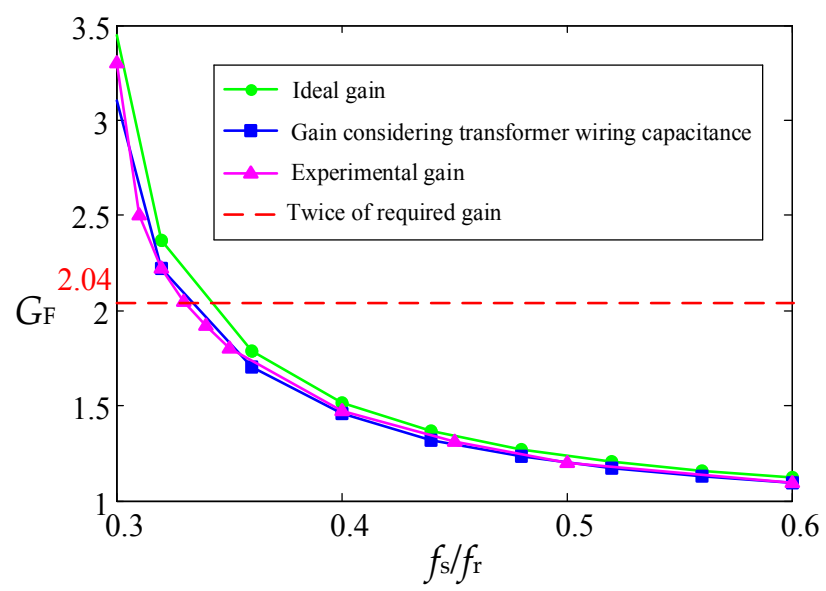

(b)

Figure 7. Voltage gain curve of full-bridge CLTC converter at light load condition. (a) Around gain of $1.02 ;(\mathbf{b})$ around again of 2.04 .

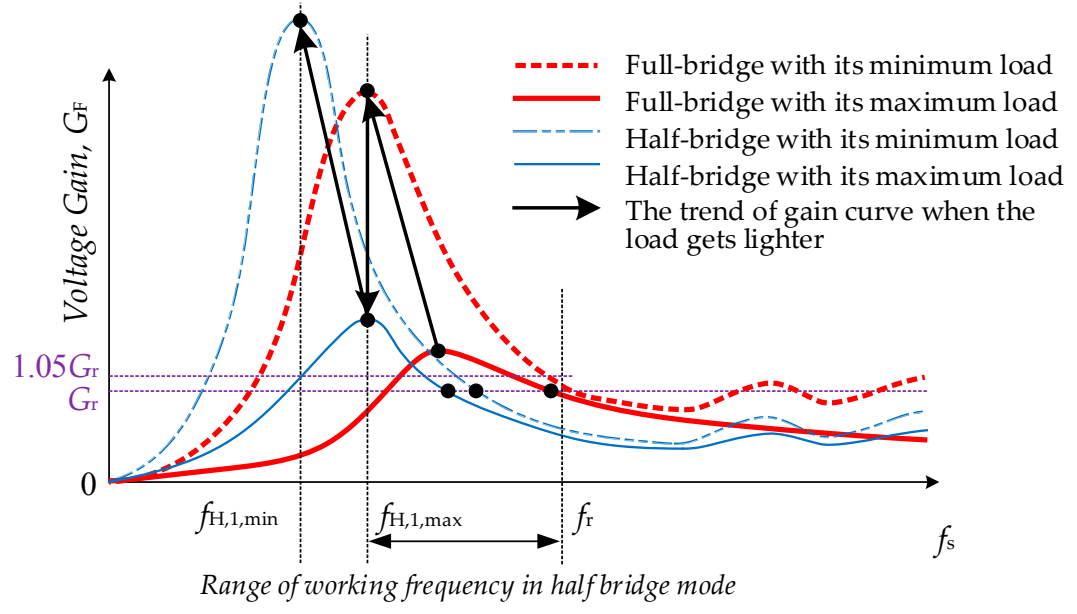

Figure 8. Voltage gain curve of CLTC converter at light load condition. 
The mechanism of transformation between full-bridge and half-bridge configuration is displayed in Figure 8. With the decrease of load in full-bridge configuration, the gain curve rises. Then, the full-bridge configuration is transformed into a half-bridge configuration, working frequency gets lower and the gain curve is monotonous around $G_{r}$. At last, half-bridge configuration is used to adapt lighter load instead of full-bridge configuration. The mechanism of transforming full-bridge into half-bridge is simple and effective, still, several considerations of the method are discussed here.

\subsection{Voltage and Current Stresses}

The stresses in both full-bridge and half-bridge configurations need to be checked. Voltage stresses of all the switches do not change. When the same power is transmitted, current stresses of LVS switches stay the same. Current stresses of HVS switches in half-bridge are twice of those in full-bridge as the AC input voltage is cut by half. Thus, the load must be light if half-bridge is adopted, to ensure the current amplitude is acceptable.

\subsection{Load and Working Frquency Range}

The peak gain should be larger than the required gain, $G_{r}$. It is because if the peak gain is smaller than $G_{r}, G_{r}$ cannot be tracked. Taking a margin of $0.05 G_{r}$ into consideration, the DC output resistance in half-bridge configuration, $R_{\mathrm{o}, \mathrm{H}}$, should satisfy the following equation:

$$
G_{\mathrm{F}, \mathrm{H}}\left(f_{\mathrm{H}, 1}, R_{\mathrm{O}, \mathrm{H}}\right) \geq 1.05 G_{\mathrm{r}}
$$

In (8), $G_{\mathrm{F}, \mathrm{H}}$ is the voltage gain of half-bridge CLTC, $f_{\mathrm{H}, 1}$ is the maximum point.

Also, $R_{\mathrm{O}, \mathrm{H}}$ should be bigger than twice of the rated resistance, $R_{\mathrm{O}, \mathrm{H}, \text { rated }}$, in full-bridge. As Section 3.2 tells, the selection of $R_{\mathrm{o}, \mathrm{H}}$ should guarantee that the current stresses in half-bridge are no bigger than those in full-bridge. Thus:

$$
R_{\mathrm{O}, \mathrm{H}} \geq 2 R_{\mathrm{O}, \mathrm{F}, \text { rated }}
$$

The working frequency of CLTC in half-bridge configuration, should be in the range of $\left[f_{\mathrm{H}, 1, \max }\right.$, $f_{\mathrm{r}}$ ]. The working frequency should be lower than $f_{\mathrm{r}}$ to avoid upturn phenomenon of gain curve. Also, when load is heavier in half-bridge, $f_{\mathrm{H}, 1}$ gets larger as Figure 8 shows, so the lower limit of the working frequency is the largest value of $f_{\mathrm{H}, 1}, f_{\mathrm{H}, 1, \max }$. In the range of $\left[f_{\mathrm{H}, 1, \max }, f_{\mathrm{r}}\right]$, the gain curve monotonously declines with working frequency, and the slope is sharper in half-bridge configuration. It is ideal for voltage regulation of CLTC.

\section{Synchronous Rectification Strategy Based on Estimation of Body Diodes' Conduction Time}

In consideration of improving the efficiency, a digital synchronous rectification strategy is proposed in forward mode. No auxiliary circuit is added. The proposed strategy adjusts conduction time of switches in LVS by calculating rectifier diodes' conduction time in half period, $t_{\mathrm{SR}}$. A whole process of calculating $t_{\mathrm{SR}}$ is proposed and verified in this section. It can be used in both full-bridge configuration and half-bridge configuration.

\subsection{Synchornous Rectification Strategy}

With the proposed digital synchronous rectification strategy, all the driving signals of HVS switches $S_{1}-S_{4}$ and LVS SR switches $S_{5}-S_{8}$ are given by STM32F series chip. The turn-on time of SR switches is set to the same with HVS main switches. But the conduction time (the interval between turn-on and turn-off time) is set with the estimation value of body diodes' conduction time in half period, $t_{\mathrm{SR}}$, so $t_{\mathrm{SR}}$ should be calculated for synchronous rectification. 


\subsection{Estimation of the Body Diodes' Conduction Time}

When working frequency of CLTC is larger than main resonant frequency, $t_{\mathrm{SR}}$ is half working period because the secondary resonance doesn't exist. However, when working frequency is smaller than main resonant frequency, $t_{\mathrm{SR}}$ is a variable with respect to $R_{\mathrm{O}}$ and $f_{\mathrm{s}}$. So discussion is focused on $t_{\mathrm{SR}}$ when working frequency is smaller than main resonant frequency.

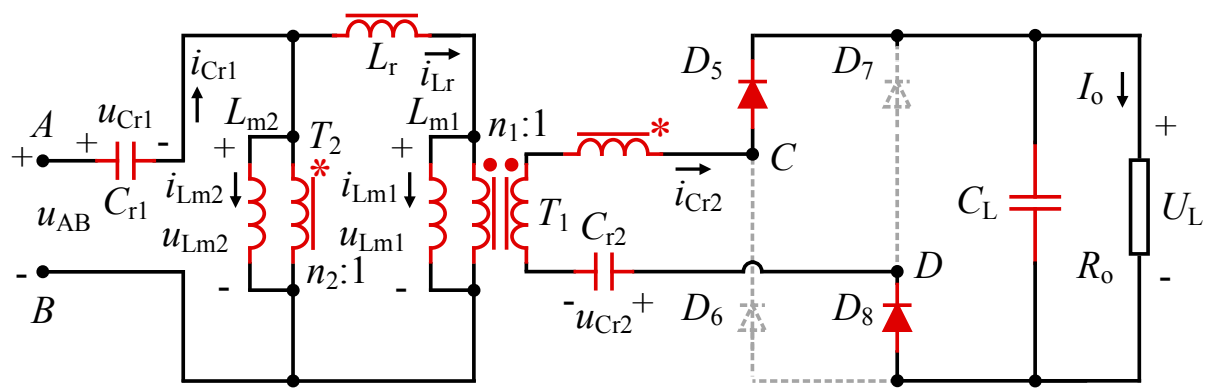

Figure 9. Topology decomposition in forward mode without synchronous rectification strategy.

In Figure 9, assuming resonant current on LVS, $i_{\mathrm{Cr} 2}$, is approximated to a sinusoidal pulse:

$$
i_{\mathrm{Cr} 2}= \begin{cases}I_{\mathrm{Cr} 2} \sin \left(\frac{\pi \times t}{t_{\mathrm{SR}}}\right), & 0 \leq t \leq t_{\mathrm{SR}} \\ 0, & t_{\mathrm{SR}} \leq t \leq T\end{cases}
$$

$I_{\mathrm{Cr} 2}$ is the peak value of $i_{\mathrm{Cr} 2}, t$ is the real time, $T_{2}$ is half period, $1 /\left(2 f_{\mathrm{s}}\right)$. The value of $u_{\mathrm{AB}}$ is $U_{\mathrm{H}}$ in this period.

By using the law of conservation of electric charge, it can be obtained that:

$$
\int_{0}^{t \mathrm{SR}} I_{\mathrm{Cr} 2} \sin \left(\frac{\pi \times t}{t_{\mathrm{SR}}}\right) d t=I_{\mathrm{O}} \times T_{2}
$$

According to (13), $I_{\mathrm{Cr} 2}$ can be expressed by:

$$
I_{\mathrm{Cr} 2}=I_{\mathrm{o}} \frac{\pi T_{2}}{2 t_{\mathrm{SR}}}
$$

The voltage of $C_{\mathrm{r} 2}$ can be expressed by:

$$
u_{\mathrm{Cr} 2}(t)=\frac{1}{C_{\mathrm{r} 2}} \int_{0}^{t} I_{\mathrm{Cr} 2} \sin \left(\frac{\pi \times t}{t_{\mathrm{SR}}}\right) d t+U_{\mathrm{Cr} 2,0}
$$

As $i_{\mathrm{Cr} 2}$ is 0 and the voltage of $C_{\mathrm{r} 2}$ stays the same during $t_{\mathrm{SR}}-T_{2}$, the following equation is found:

$$
U_{\mathrm{Cr} 2,0}=-u_{\mathrm{Cr} 2}\left(T_{2}\right)=-u_{\mathrm{Cr} 2}\left(t_{\mathrm{SR}}\right)
$$

Applying (15) into (16), the $U_{\mathrm{Cr} 2,0}$ can be expressed by:

$$
U_{\mathrm{Cr} 2,0}=-\frac{t_{\mathrm{SR}}^{2} U_{\mathrm{L}}}{2 C_{\mathrm{r} 2} T_{2} R_{\mathrm{o}}}
$$

The voltage of magnetizing inductance $L_{\mathrm{m} 1}$ and $L_{\mathrm{m} 2}, u_{\mathrm{Lm} 1}$ and $u_{\mathrm{Lm} 2}$, can form following equations:

$$
\left\{\begin{array}{l}
\frac{u_{\mathrm{Lm} 1}(t)}{n_{1}}+\frac{u_{\mathrm{Lm} 2}(t)}{n_{2}}=U_{\mathrm{L}}+U_{\mathrm{Cr} 2}(t) \\
\left(1+\frac{L_{\mathrm{r}}}{L_{\mathrm{m} 1}}\right) u_{\mathrm{Lm} 1}(t)+\frac{1}{n_{1}} L_{\mathrm{r}} \frac{d i_{\mathrm{Cr} 2}(t)}{d t}=u_{\mathrm{Lm} 2}(t)
\end{array}\right.
$$


so $u_{\mathrm{Lm} 2}$ can be expressed by:

$$
u_{\mathrm{Lm} 2}(t)=\frac{\frac{n_{2}}{n_{1}} L_{\mathrm{r}} \frac{d i_{\mathrm{Cr} 2}(t)}{d t}+\left(1+\frac{L_{\mathrm{r}}}{L_{\mathrm{m} 1}}\right) n_{1} n_{2}\left[U_{\mathrm{L}}+U_{\mathrm{Cr} 2}(t)\right]}{n_{2}+n_{1}\left(1+\frac{L_{\mathrm{r}}}{L_{\mathrm{m} 1}}\right)}
$$

The instantaneous voltage between HVS full-bridge legs, $u_{\mathrm{AB}}$, can be expressed as:

$$
u_{\mathrm{AB}}(t)=U_{\mathrm{Cr} 1,0}+\frac{1}{C_{\mathrm{r} 1}} \int_{0}^{t} i_{\mathrm{Cr} 1}(t) d t+u_{\mathrm{Lm} 2}(t)
$$

where, $U_{\mathrm{Cr} 1,0}$ is the initial voltage of resonant capacitor $C_{\mathrm{r} 1}$ at $t_{0}$, and the instantaneous current of $C_{\mathrm{r} 1}$, $i_{\mathrm{Cr} 1}$, can be expressed as:

$$
i_{\mathrm{Cr} 1}(t)=i_{\mathrm{Lm} 1}(t)+i_{\mathrm{Lm} 2}(t)+\left(\frac{1}{n_{1}}+\frac{1}{n_{2}}\right) i_{\mathrm{Cr} 2}(t)
$$

In order to simplify calculation process, $L_{\mathrm{m} 2}$ is supposed to be subject to $u_{\mathrm{AB}}$ during $0-t_{\mathrm{SR}}$. So $i_{\mathrm{Lm} 2}$ and $i_{\mathrm{Lm} 1}$ can be expressed as linearly increasing currents:

$$
\begin{gathered}
i_{\mathrm{Lm} 1}(t)=\frac{U_{\mathrm{H}}}{2\left(L_{\mathrm{m} 1}+L_{\mathrm{r}}\right)} t+I_{\mathrm{Lm} 1,0} \\
i_{\mathrm{Lm} 2}(t)=\frac{U_{\mathrm{H}}}{2 L_{\mathrm{m} 2}} t+I_{\mathrm{Lm} 2,0}
\end{gathered}
$$

$I_{\mathrm{Lm} 1,0}$ and $I_{\mathrm{Lm} 2,0}$ is the initial value of $I_{\mathrm{Lm} 1}$ and $I_{\mathrm{Lm} 2}$ :

$$
\begin{gathered}
I_{\mathrm{Lm} 1,0}=-\frac{U_{\mathrm{H}} \times t_{\mathrm{SR}}}{4\left(L_{\mathrm{m} 1}+L_{\mathrm{r}}\right)} \\
I_{\mathrm{Lm} 2,0}=-\frac{U_{\mathrm{H}} \times t_{\mathrm{SR}}}{4 L_{\mathrm{m} 2}}
\end{gathered}
$$

Realizing that $u_{\mathrm{AB}}(t)=U_{\mathrm{H}}$ and substituting (19) and (21) into (20), gives:

$$
U_{\mathrm{H}}=U_{\mathrm{Cr} 1,0}+\frac{1}{C_{\mathrm{r} 1}} \int_{0}^{t}\left[i_{\mathrm{Lm} 1}(t)+i_{\mathrm{Lm} 2}(t)+\left(\frac{1}{n_{1}}+\frac{1}{n_{2}}\right) i_{\mathrm{Cr} 2}(t)\right] d t+\frac{\frac{n_{2}}{n_{1}} L_{\mathrm{r}} \frac{d i_{\mathrm{C} 2}(t)}{d t}+\left(1+\frac{L_{\mathrm{r}}}{L_{\mathrm{m} 1}}\right) n_{1} n_{2}\left[U_{\mathrm{L}}+U_{\mathrm{Cr} 2}(t)\right]}{n_{2}+n_{1}\left(1+\frac{L_{\mathrm{r}}}{L_{\mathrm{m} 1}}\right)}
$$

Getting the derivative of the above equation:

$$
0=-D \frac{\pi^{2}}{t_{\mathrm{SR}}^{2}} \sin \left(\frac{\pi \times t}{t_{\mathrm{SR}}}\right)+E \times \sin \left(\frac{\pi \times t}{t_{\mathrm{SR}}}\right)+F \times t_{\mathrm{SR}} \times t+\frac{I_{\mathrm{Lm} 1,0}+I_{\mathrm{Lm} 2,0}}{I_{\mathrm{Cr} 2}}
$$

In (27), $D, E, F$ are:

$$
\begin{gathered}
D=\frac{C_{\mathrm{r} 1} n_{2} L_{\mathrm{r}}}{n_{1}\left[n_{2}+n_{1}\left(1+\frac{L_{\mathrm{r}}}{L_{\mathrm{m} 1}}\right)\right]} \\
E=\frac{C_{\mathrm{r} 1}\left(1+\frac{L_{\mathrm{r}}}{L_{\mathrm{m} 1}}\right) n_{1} n_{2}}{C_{\mathrm{r} 2}\left[n_{2}+n_{1}\left(1+\frac{L_{\mathrm{r}}}{L_{\mathrm{m} 1}}\right)\right]}+\frac{1}{n_{1}}+\frac{1}{n_{2}} \\
F=\left[\frac{1}{2\left(L_{\mathrm{m} 1}+L_{\mathrm{r}}\right)}+\frac{1}{2 L_{\mathrm{m} 2}}\right] \frac{U_{\mathrm{H}}}{I_{\mathrm{Cr} 2} t_{\mathrm{SR}}}
\end{gathered}
$$

$U_{\mathrm{H}}$ can be expressed as $U_{\mathrm{L}} / M_{\mathrm{SD}}$, so $F$ can be simplified by:

$$
F=\left[\frac{1}{2\left(L_{\mathrm{m} 1}+L_{\mathrm{r}}\right)}+\frac{1}{2 L_{\mathrm{m} 2}}\right] \frac{2 R_{\mathrm{o}}}{\pi T_{2} M_{\mathrm{SD}}}
$$


$\frac{I_{\mathrm{Lm} 1,0}+I_{\mathrm{Lm} 2,0}}{I_{\mathrm{Cr} 2}}$ is close to 0 as $I_{\mathrm{Cr} 2}$ is much larger than $I_{\mathrm{Lm} 1,0}+I_{\mathrm{Lm} 2,0}$. When $t$ is close to $0, \frac{\pi \times t}{t_{\mathrm{SR}}} \approx$ $\sin \left(\frac{\pi \times t}{t_{\mathrm{SR}}}\right), t_{\mathrm{SR}}$ is the solution of (27):

$$
t_{\mathrm{SR}}=\sqrt{\frac{-\pi E+\pi \sqrt{E^{2}+4 D F \pi}}{2 F}}
$$

In Figure 10, the normalized estimated conduction time $t_{\mathrm{SR}} / T_{2}$ versus normalized operating frequency $f_{\mathrm{s}} / f_{\mathrm{r}}$ and different load (dots-simulation, solid lines-theoretical prediction). Figure 10 reveals good agreement between theoretical values and simulation results. The curve of $t_{\mathrm{SR}} / T_{2}$ is basically proportional to $f_{\mathrm{s}} / f_{\mathrm{r}}$, and grows with the increase of load.

Based on the above analysis, the conduction time of LVS switches is set to estimated conduction time $t_{\mathrm{SR}}$ obtained when load is the lightest, so the conduction time of LVS switches in the proposed synchronous rectification strategy is not relevant to the load. It is a parameter changing with operating frequency. LVS switches turn on firstly to reduce conduction loss. Then, as estimated conduction time $t_{\mathrm{SR}}$ is a little smaller than the real conduction time of LVS body diodes, the body diodes of LVS switches conduct until the LVS resonant current becomes zero. Efficiency is not affected because the duration when body diodes conduct is short. The proposed digital synchronous rectification strategy is simple and effective, the effects are discussed in sections below.

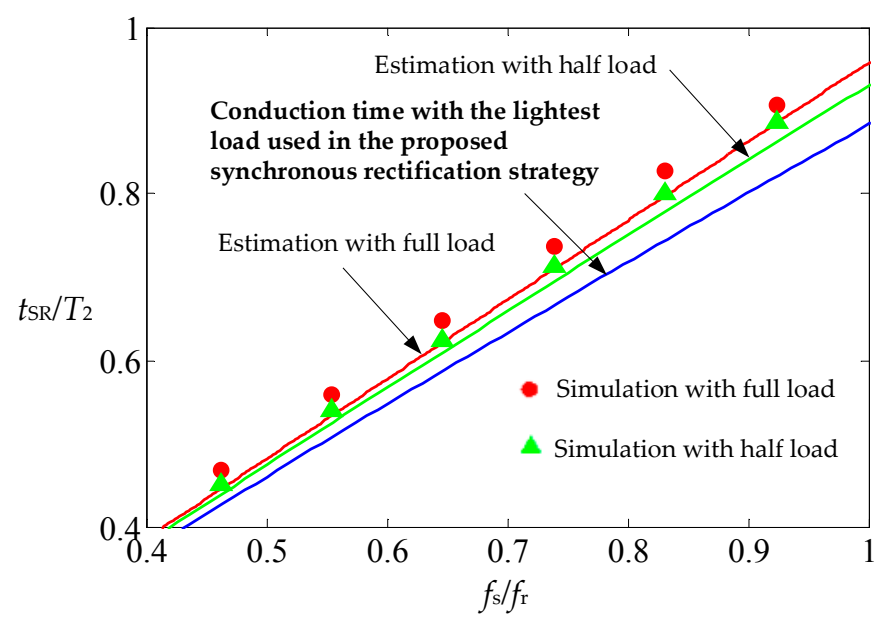

Figure 10. Normalized estimated conduction time $t_{\mathrm{SR}} / T_{2}$ in calculation and simulation.

\section{Power Loss Analysis}

The power loss of converters is the key factor for component selection and design. In this section, the power loss distribution is calculated with mathematical models and compared with different LVS DC voltages. The HVS DC voltage of the converter stays the same. The power loss with half-bridge configuration and synchronous rectification strategy are discussed in this section, too.

Before further analysis, several parameters are defined as follows, $P_{\mathrm{HSW}, \text { off }}$ is the turn-off loss of HVS power switches, $P_{\mathrm{HSW}}$,con is the conduction loss of HVS power switches, $P_{\mathrm{LSW} \text {,off }}$ is the turn-off loss of LVS power switches, $P_{\mathrm{LSW}, \text { con }}$ is the conduction loss of LVS power switches, $P_{\mathrm{L}}$ is the power loss of resonant inductor, $P_{\mathrm{T}, \Sigma}$ is the total power loss of transformers, $P_{\mathrm{WIRE}, \mathrm{con}}$ is the conduction loss in printed circuit board and copper bar, $P_{\mathrm{HD}}$ is the power loss of HVS diodes, $P_{\mathrm{LD}}$ is the power loss of LVS body diodes in power switches.

\subsection{Loss Distribution with Different LVS DC Voltages}

Power loss distribution with $5 \mathrm{~kW}$ load in forward and backward mode is shown in Figure 11. The power loss distribution is conducted with three LVS DC voltages of 42,50 and $58 \mathrm{~V}$ and the HVS 
voltage of $400 \mathrm{~V}$. In forward mode, the column of " $50 \mathrm{~V}$ " is obtained around main resonant frequency, while the column of " $42 \mathrm{~V}$ " is obtained with higher frequency and column of " $58 \mathrm{~V}$ " is obtained with lower frequency. In backward mode, the column of " $50 \mathrm{~V}$ " is obtained around main resonant frequency, while the column of " $42 \mathrm{~V}$ " is obtained with lower frequency and column of " $58 \mathrm{~V}$ " is obtained with higher frequency.

Loss comparison in forward mode with $5 \mathrm{~kW}$ load and different LVS DC voltages

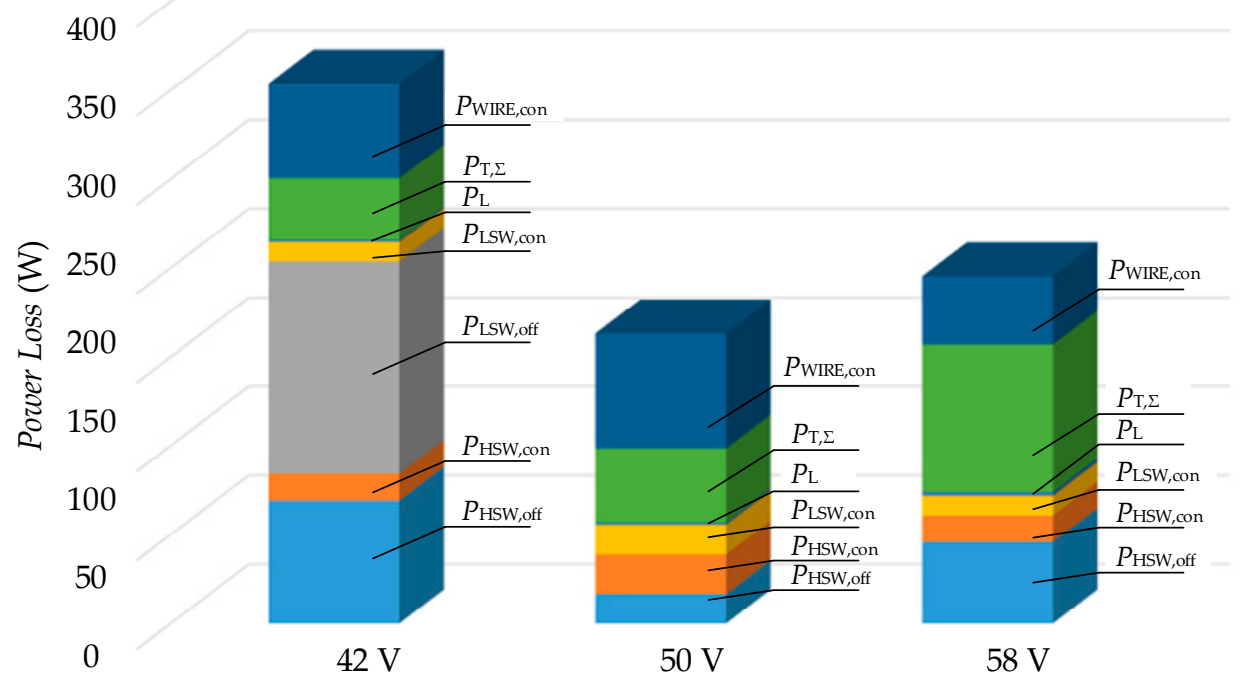

(a)

Loss comparison in backward mode with $5 \mathrm{~kW}$ load and different LVS DC voltages

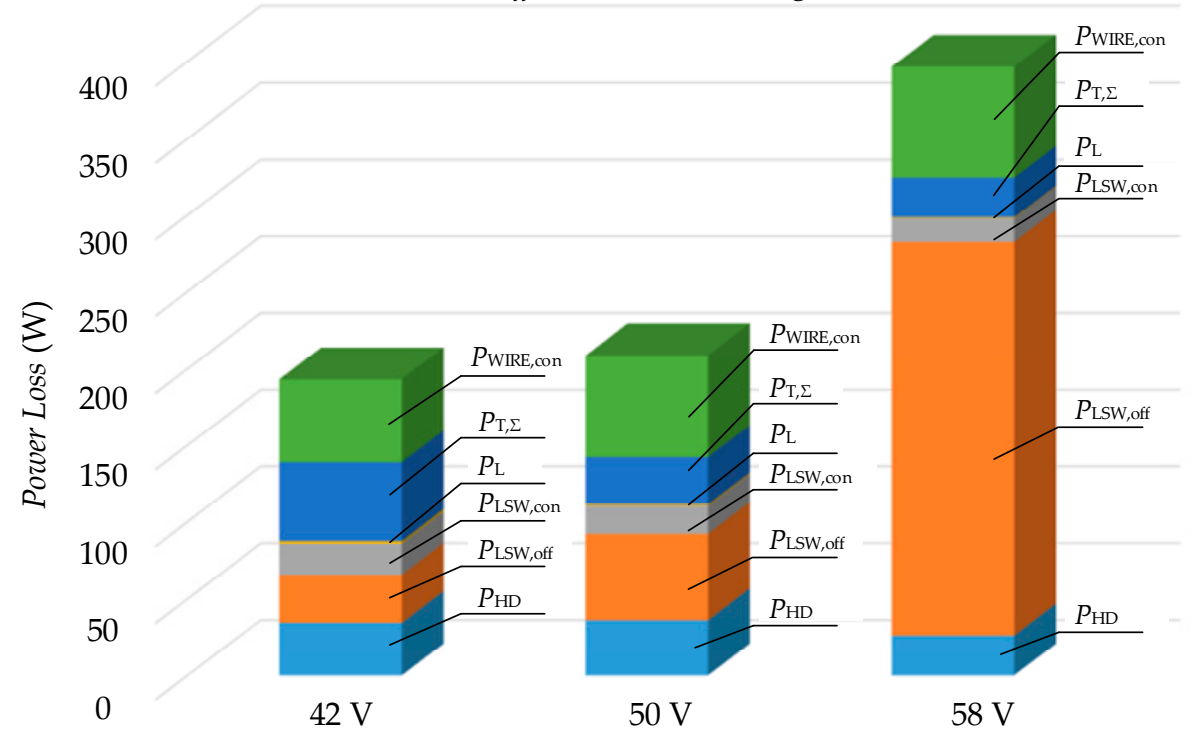

(b)

Figure 11. The power loss distribution with $5 \mathrm{~kW}$ and different LVS DC voltages: (a) forward mode; (b) backward mode.

$P_{\mathrm{HSW}, \text { off }}$ and $P_{\mathrm{LSW}, \text { off }}$ are the dominant power losses. $P_{\mathrm{L}}$ and $P_{\mathrm{T}, \Sigma}$ change little with the change of LVS DC voltage. $P_{\text {WIRE,con }}$ is large due to proximity effect and skin effect. The column of " $42 \mathrm{~V}$ " in forward mode and the column of " $58 \mathrm{~V}$ " in backward mode have greater power loss compared to the 
other columns. This is mainly because $P_{\mathrm{HSW}, \text { off }}$ and $P_{\mathrm{LSW}, \text { off }}$ are larger due to larger turn-off currents and higher working frequencies. The HVS switches are SiC power devices, and the LVS switches are $\mathrm{Si}$ power devices. Compared to LVS switches, the HVS switches have less turn-off delay time and fall time. So the switching loss of LVS switches is larger than that of HVS switches. Thus, the efficiency in forward mode is higher than that in backward mode in general.

\subsection{Power Loss Distribution and Comparison between Full-Bridge and Half-Bridge Configuration}

The power loss distribution and comparison between full-bridge and half-bridge configuration is made to demonstrate the advantage of half-bridge configuration in efficiency. Taking forward mode for example, changing from full-bridge configuration to half-bridge configuration has impacts as follows:

(1) $P_{\mathrm{HSW}, \text { off }}$ and $P_{\mathrm{LSW}, \text { off }}$ decrease largely. In forward mode, switches staying on on-off mode in HVS decrease from 4 to 2, and their working frequency decreases from $160 \mathrm{kHz}$ to around $40 \mathrm{kHz}$. So $P_{\mathrm{HSW}, \text { off }}$ decreases largely with half-bridge configuration. Also, $P_{\mathrm{LSW}, \text { off }}$ decreases with less turn-off current and lower working frequency.

(2) The conduction loss of all devices increases. Resonant current on HVS increases to about twice, so $P_{\mathrm{HSW}, \text { con }}$, conduction loss of resonant inductor and primary windings of transformers are amplified. However, as resonant current on LVS changes little, $P_{\mathrm{LSW}, \mathrm{con}}$ and the conduction loss of secondary windings in transformers stay the same.

(3) Core loss of resonant inductor and transformers stays the same. In half-bridge LLC, working frequency $f_{\mathrm{s}}$ decreases. However, $B_{\max }$, the peak flux density, increases because peak value of current increases. With Steinmetz's equation $P_{\text {core }}=K f_{\mathrm{s}}{ }^{\alpha} B_{\max }{ }^{\beta} V_{\mathrm{e}}$, the core losses of resonant inductor and transformers in half-bridge configuration change little.

Figure 12a shows power loss distribution and comparison with load of $200 \mathrm{~W}$ in forward mode. Efficiencies of half-bridge and full-bridge configuration are $87.7 \%$ and $86.7 \%$. The power loss distribution is in accordance with the above analysis. Compared to full-bridge configuration, efficiency is a little higher in half-bridge configuration.

Figure $12 \mathrm{~b}$ shows power loss distribution and comparison with load of $200 \mathrm{~W}$ in backward mode. $P_{\mathrm{LSW}, \text { off }}$ gets much smaller in half-bridge configuration. The power loss is cut down by $26.7 \%$ and the efficiency is $81.5 \%$ in half-bridge configuration.

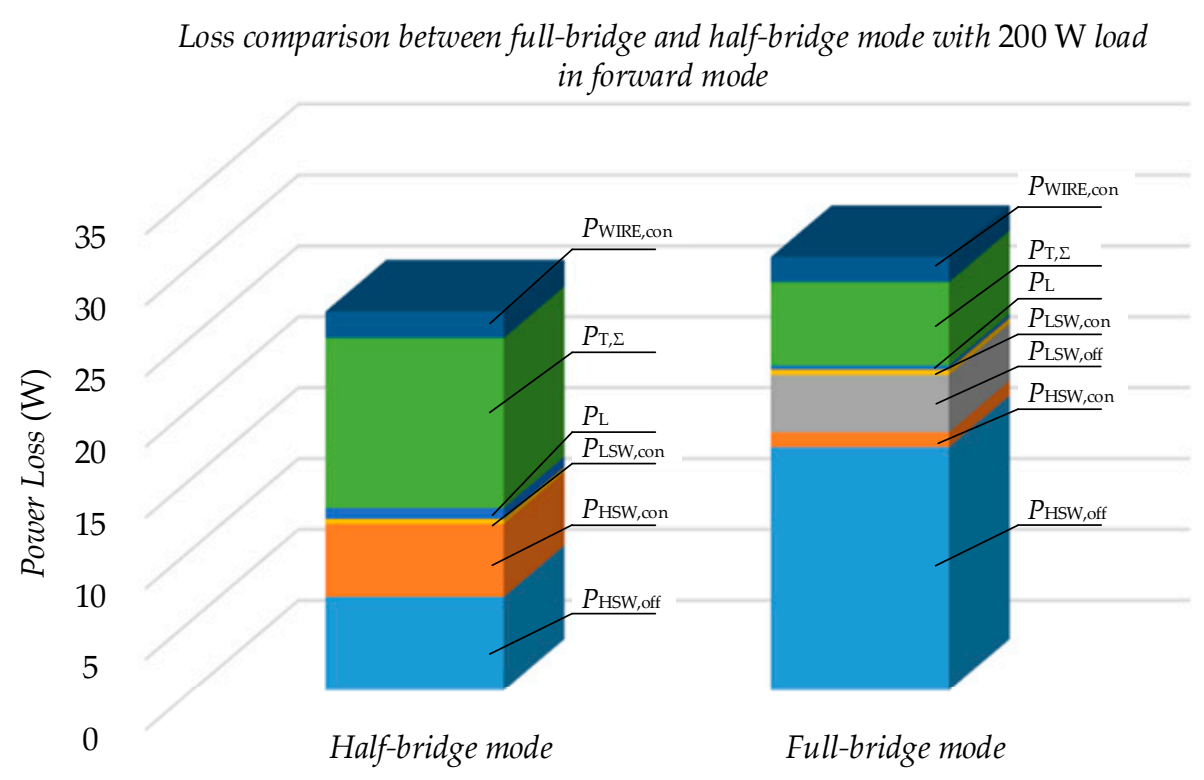

(a)

Figure 12. Cont. 


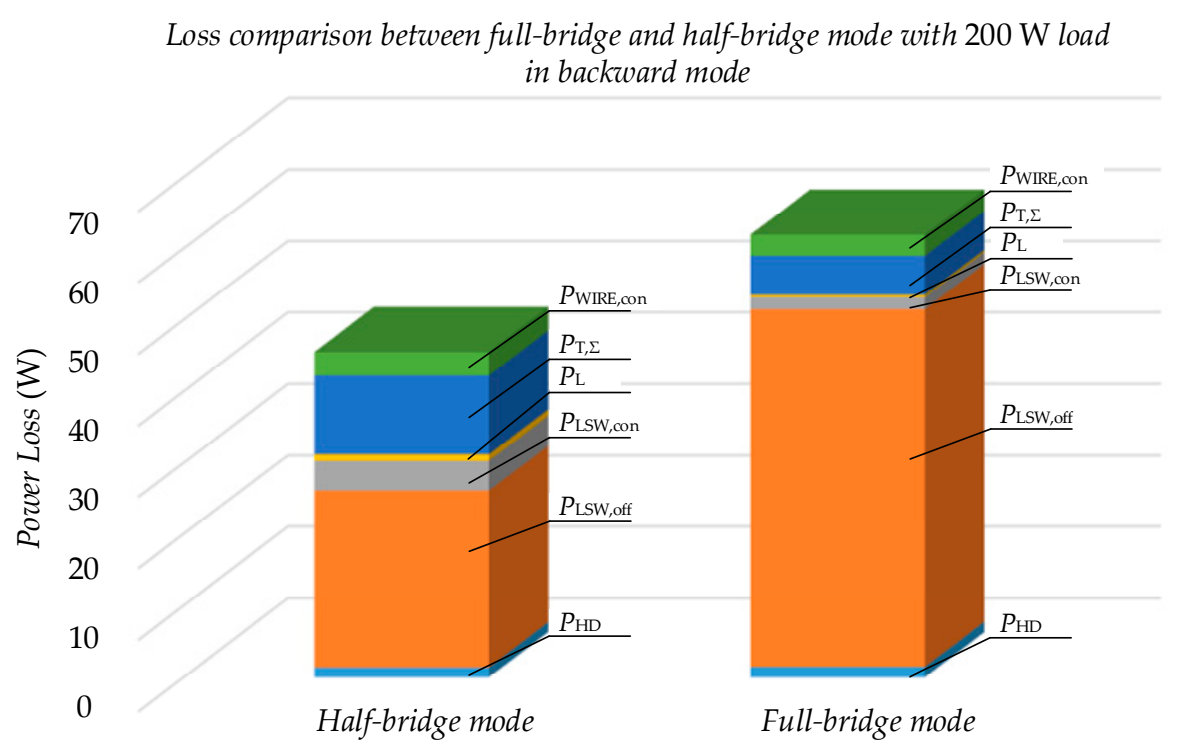

(b)

Figure 12. The power loss distribution and comparison between full-bridge and half-bridge configuration with $200 \mathrm{~W}$ load: (a) forward mode; (b) backward mode.

\subsection{Power Loss Distribution and Comparison with and without Synchronous Strategy}

Figure 13 shows the power loss distribution and comparison with and without synchronous strategy. When body diodes of LVS switches are used to realize rectification, $P_{\mathrm{LD}}$ is quite large with diode forward voltage of $0.9 \mathrm{~V}$. However, the drain-source on-state resistance of LVS switches is only $0.7 \mathrm{~m} \Omega$. Thus, with the use of the proposed synchronous strategy, $P_{\mathrm{LSW}, \mathrm{con}}$ is quite small. The total loss is cut by $49 \%$ with the use of synchronous strategy, showing the advantage in power loss reduction and efficiency enhancement.

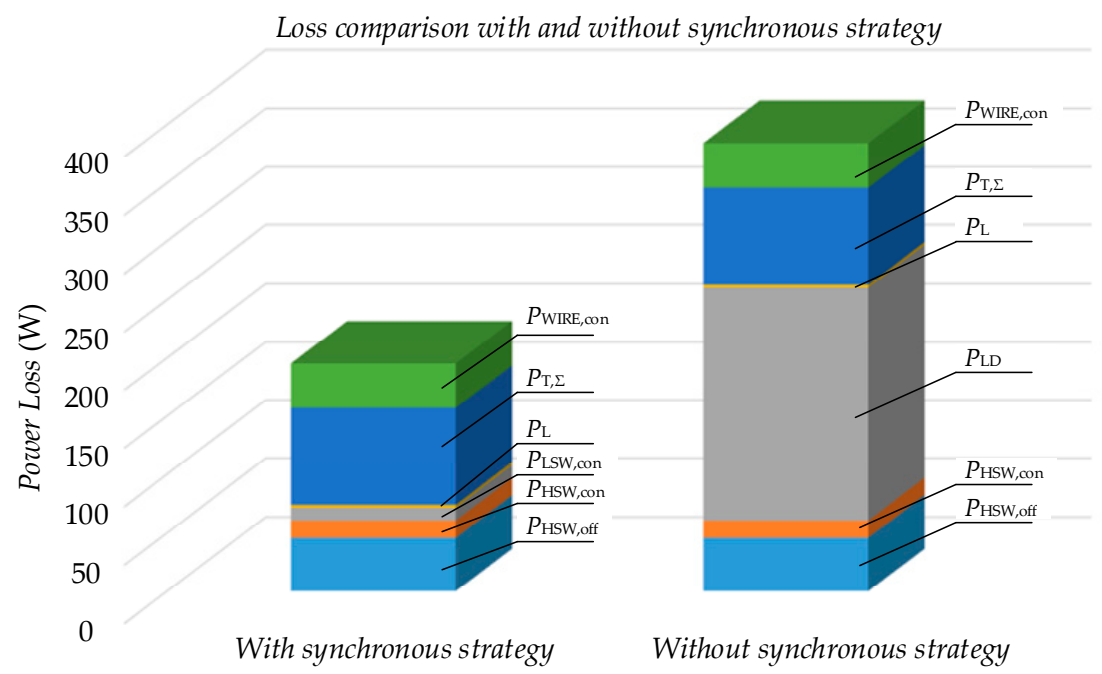

Figure 13. The power loss distribution and comparison with and without synchronous strategy.

\section{Experimental Results}

A $5 \mathrm{~kW}$ prototype is built in the laboratory to verify the above analysis. The parameters of the components are listed in Table 1. 
Table 1. Parameters of the converter.

\begin{tabular}{cc}
\hline Component & Model/Value \\
\hline Rated power & $5 \mathrm{~kW}$ \\
HVS DC voltage & $380-420 \mathrm{~V}$ \\
LVS DC voltage & $42-58 \mathrm{~V}$ \\
$\mathrm{~S}_{1}, \mathrm{~S}_{2}, \mathrm{~S}_{3}, \mathrm{~S}_{4}$ & C3M0065090D \\
$\mathrm{S}_{5}, \mathrm{~S}_{6}, \mathrm{~S}_{7}, \mathrm{~S}_{8}$ & 4 IPB036N12N3G in parallel \\
$\mathrm{D}_{1}, \mathrm{D}_{2}, \mathrm{D}_{3}, \mathrm{D}_{4}$ & C3D $30065 \mathrm{D}$ \\
$L_{\mathrm{m} 1}$ & $140 \mu \mathrm{H}$ \\
$n_{1}$ & $11: 1$ \\
$L_{\mathrm{m} 2}$ & $875 \mu \mathrm{H}$ \\
$n_{2}$ & $20: 1$ \\
$L_{\mathrm{r}}$ & $57 \mu \mathrm{H}$ \\
$C_{\mathrm{r} 1}$ & $251 \mathrm{nF}$ \\
$C_{\mathrm{r} 2}$ & $10 \mu \mathrm{F}$ \\
$t_{\mathrm{dt} \_\mathrm{F}}$ & $200 \mathrm{~ns}$ \\
$t_{\mathrm{dt} \_\mathrm{B}}$ & $200 \mathrm{~ns}$ \\
\hline
\end{tabular}

Figure 14 shows that ZVS of power switches can be realized in both forward and backward modes. In forward mode, the D-S voltage of $S_{1}$ decreases to 0 , before the driving signal of $S_{1}$ comes. In backward mode, the D-S voltage of $S_{5}$ decreases to 0 , before the driving signal of $S_{5}$ comes. The dead time of $200 \mathrm{~ns}$ is wide enough for both HVS and LVS power switches, while the efficiency is not greatly reduced.

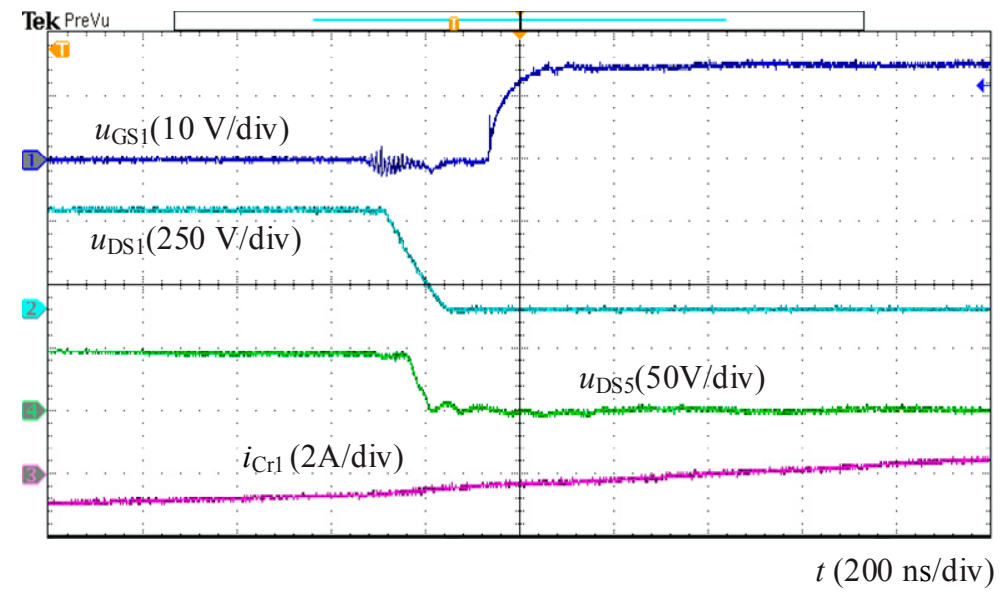

(a)

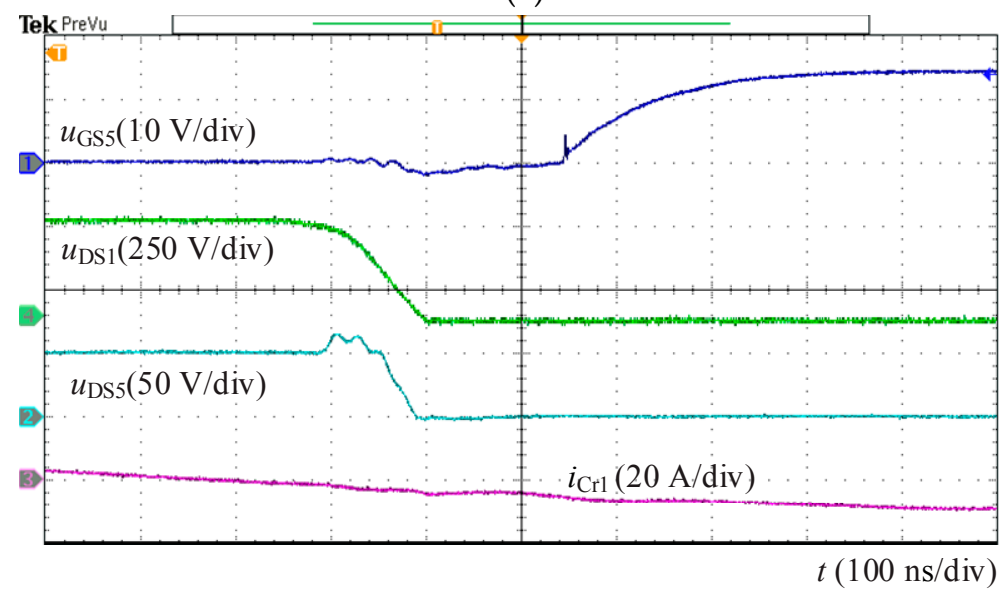

(b)

Figure 14. Experimental results of ZVS: (a) forward mode, $500 \mathrm{~W}$; (b) backward mode, $5 \mathrm{~kW}$. 
Figure 15 shows experiment results in forward mode. The $t_{\mathrm{SR}}$ is $4.6 \mu \mathrm{s}$ in Figure 15a with working frequency of $60 \mathrm{kHz}$ and load of $3.5 \mathrm{~kW}$. The $t_{\mathrm{SR}}$ is $4.5 \mu$ s with Equation (25) and $4.3 \mu \mathrm{s}$ in the proposed synchronous rectification strategy, which is basically consistent with the experiment results. The accuracy of calculation and the effectiveness of proposed synchronous rectification strategy are verified through experiments. Figure $15 \mathrm{~b}$ shows the waveforms around main resonant frequency. The resonant current is quite close to sinusoidal wave. The power loss is lower because of smaller turn-off loss in this situation.

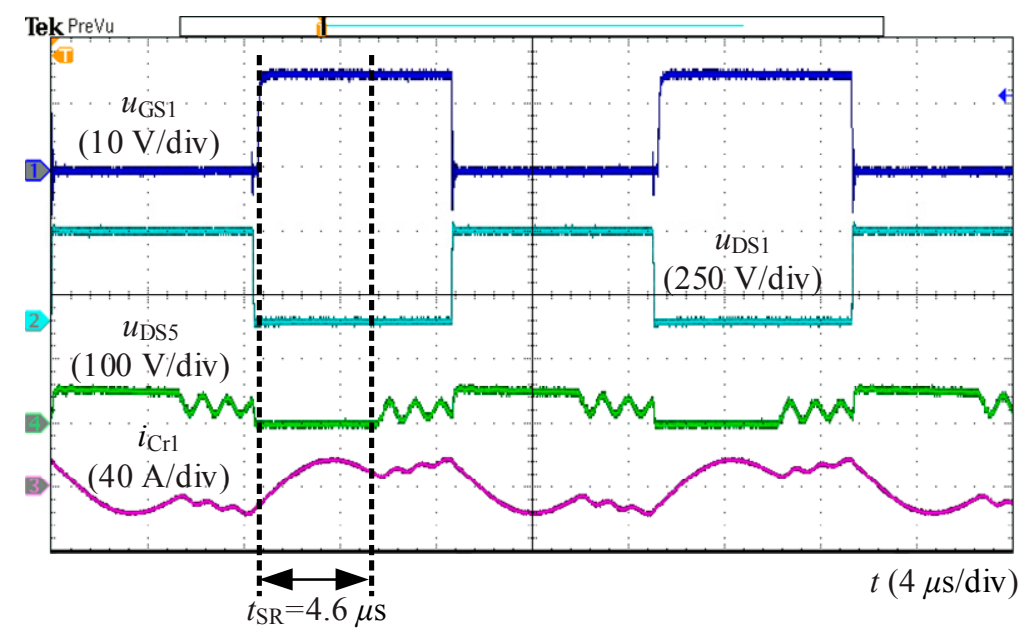

(a)

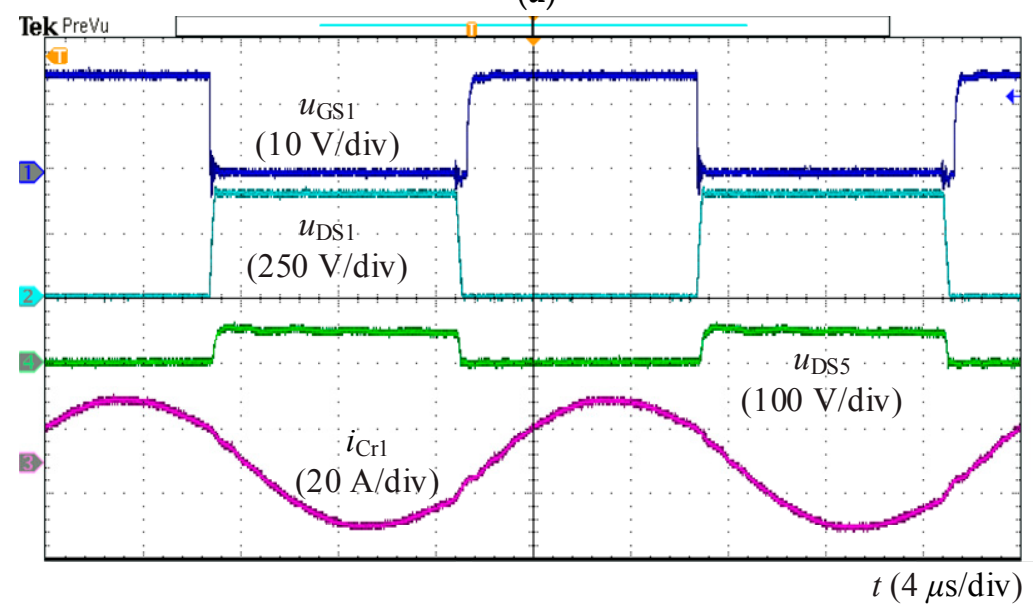

(b)

Figure 15. Experimental results in forward mode: (a) $60 \mathrm{kHz}, 3.5 \mathrm{~kW}$; (b) $100 \mathrm{kHz}, 5 \mathrm{~kW}$.

Figure 16 shows experiment results in backward mode. In Figure 16a, secondary resonance does not happen, so ZCS of HVS diodes cannot be realized. In Figure 16b, the resonant current is quite close to sinusoidal wave around main resonant frequency. The power loss in Figure 16b is lower because of smaller turn-off loss. 


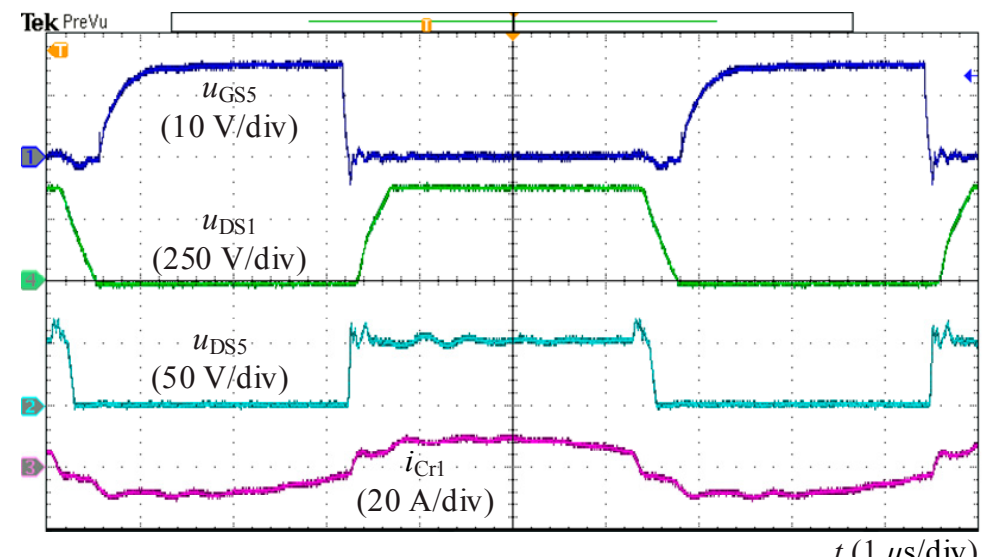

(a)

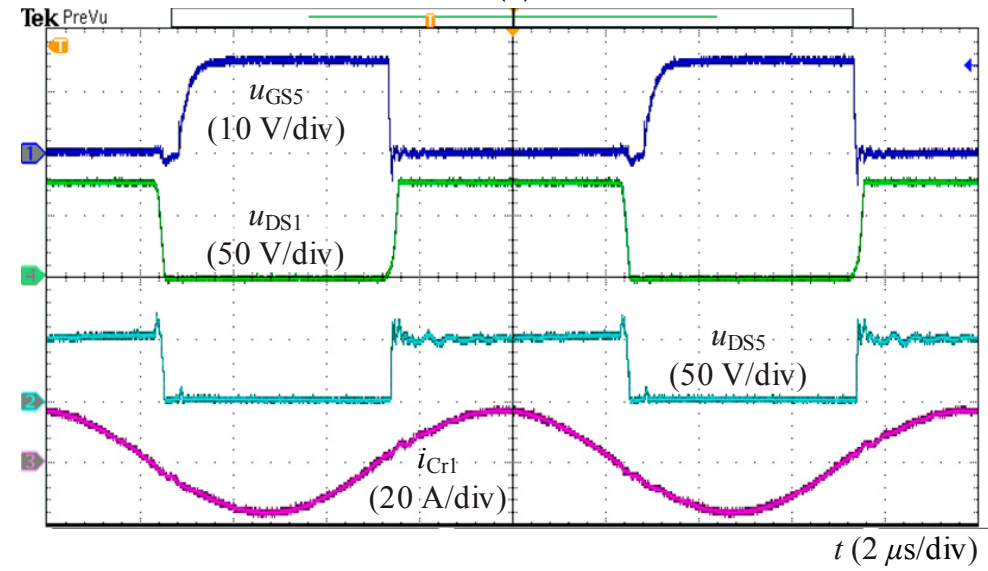

(b)

Figure 16. Experimental results in backward mode: (a) $160 \mathrm{kHz}, 2.5 \mathrm{~kW}$; (b) $100 \mathrm{kHz}, 5 \mathrm{~kW}$.

Experiments are conducted to verify the effectiveness of half-bridge configuration at light load condition in Figure 17. In both forward and backward mode, the adoption of half-bridge configuration can track a gain of 1.02. Compared to full-bridge, the fall of working frequency in half-bridge configuration reduces turn-off loss, which is very good for efficiency.

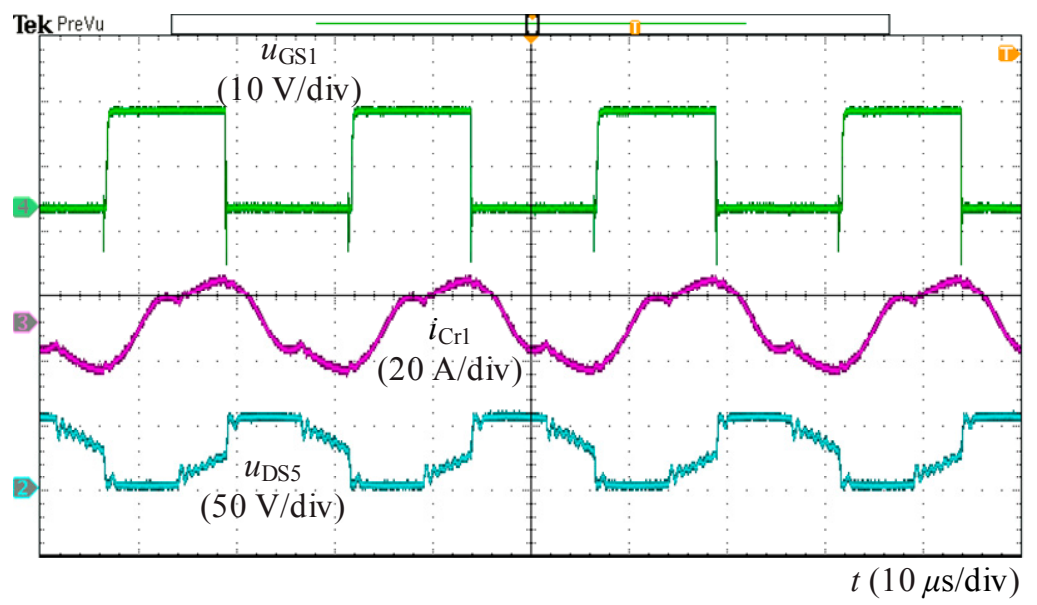

(a)

Figure 17. Cont. 


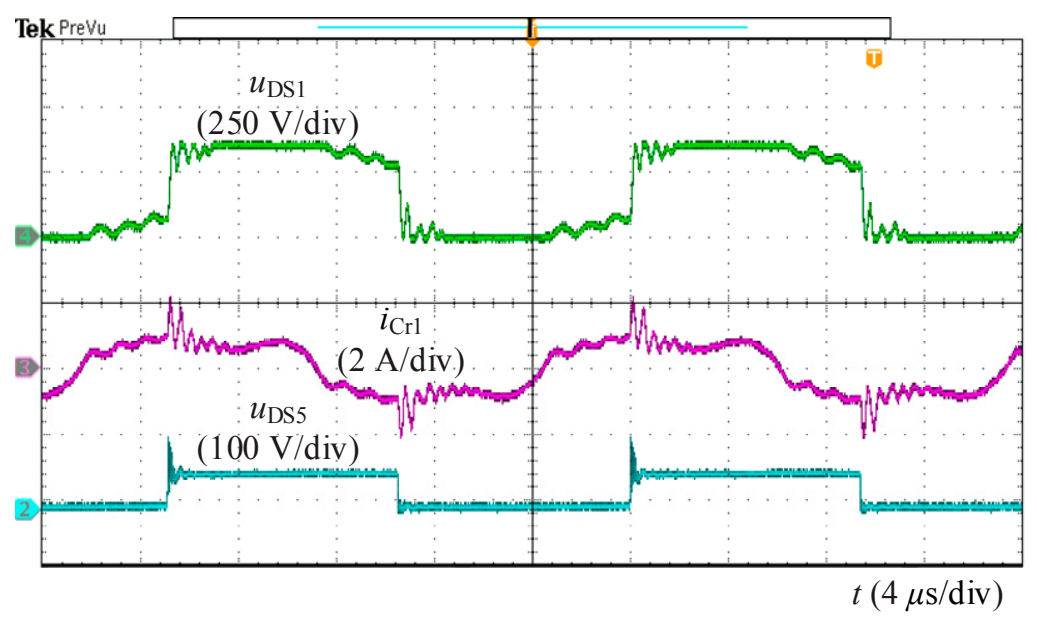

(b)

Figure 17. Experimental results with half-bridge configuration at light load condition: (a) forward mode, $200 \mathrm{~W}$; (b) backward mode, $200 \mathrm{~W}$.

Efficiency comparison is conducted with experiments at light load condition. In Table 2, the efficiency in half-bridge configuration is higher than that in full-bridge, which is in accord with analysis in Section 5.2. The advantage of half-bridge configuration is verified through experiments.

Table 2. Efficiency comparison with load of $200 \mathrm{~W}$.

\begin{tabular}{ccc}
\hline Type & Half-Bridge & Full-Bridge \\
\hline Forward & $87.3 \%$ & $83.0 \%$ \\
Backward & $82.1 \%$ & $70.9 \%$ \\
\hline
\end{tabular}

Efficiencies of the proposed converter with different loads and LVS DC voltages are measured and plotted in Figure 18. The efficiency with $5 \mathrm{~kW}$ load and 50 V LVS DC voltage is $95.9 \%$ and $94.9 \%$ in forward and backward mode. The maximum efficiency of the converter is $97.0 \%$, with load of $2 \mathrm{~kW}$ and LVS DC voltage of $50 \mathrm{~V}$ in forward mode. Due to less turn-off currents and lower working frequencies, the efficiency of " $58 \mathrm{~V}$ " or " $50 \mathrm{~V}$ " is higher than that of " $42 \mathrm{~V}$ " in forward mode and the efficiency of " $42 \mathrm{~V}$ " or " $50 \mathrm{~V}$ " is higher than that of " $58 \mathrm{~V}$ " in backward mode. It is in accord with theoretical analysis in Section 5. High efficiency can be achieved in a wide load range. Even with $1 \mathrm{~kW}$ load, the efficiency is still over $92 \%$ due to the wide ZVS soft switching operation range and little turn-off currents.

The comparative experiments are conducted with and without synchronous rectification strategy when LVS DC voltage is $50 \mathrm{~V}$, displayed as " $50 \mathrm{~V}$ " and "Diode $50 \mathrm{~V}$ ". From the converter power loss distribution, the LVS diode conduction loss is the dominant part in "Diode $50 \mathrm{~V}$ ", which occupies nearly $50 \%$ of the total power loss. Experiment results show that the efficiency is improved largely with the help of the proposed synchronous rectification strategy. 


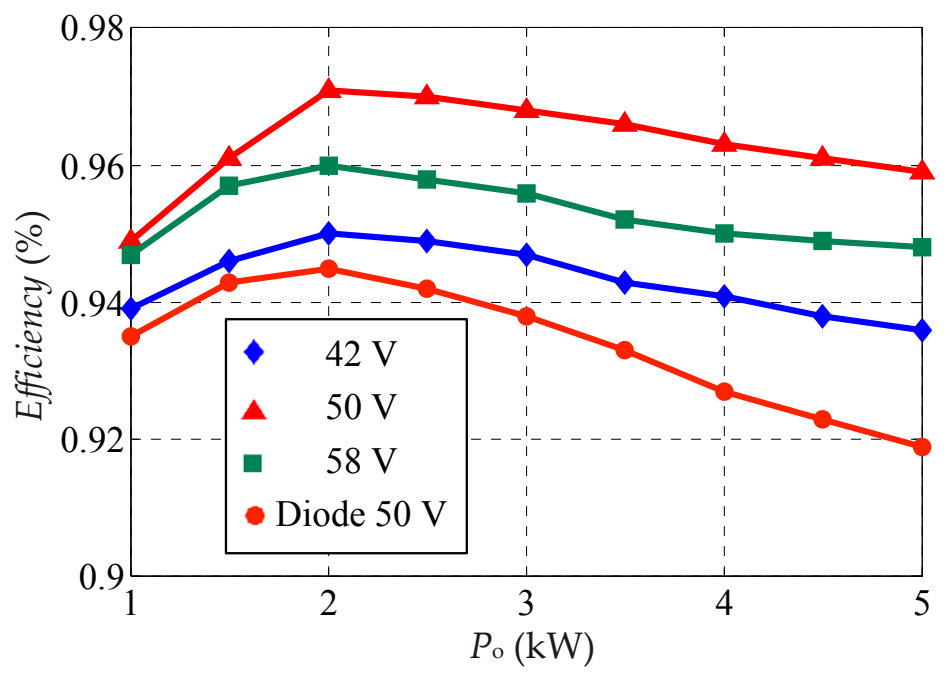

(a)

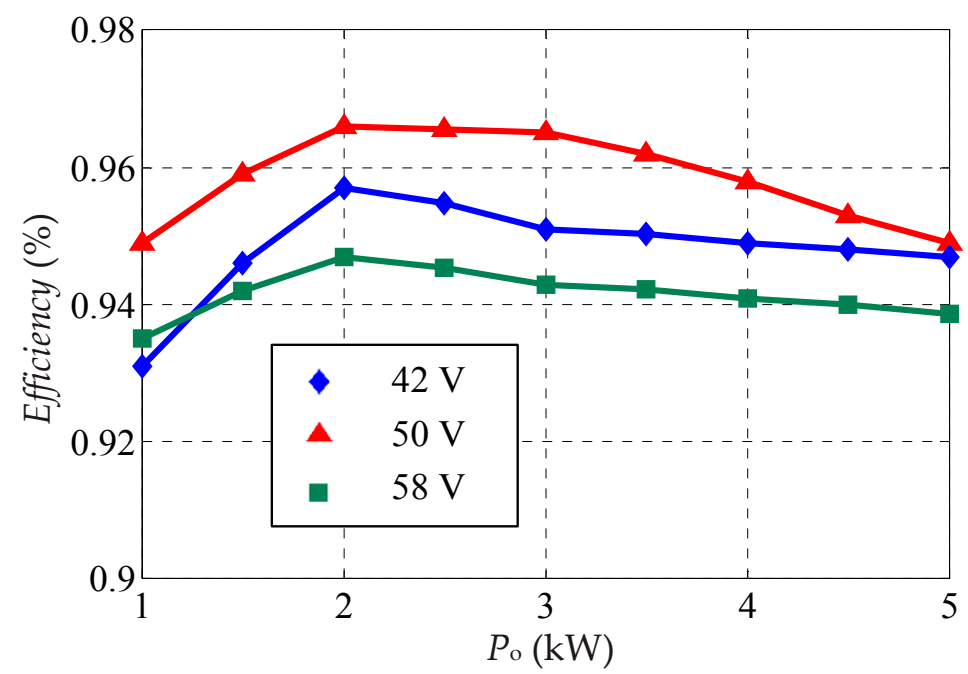

(b)

Figure 18. Measured efficiency: (a) forward mode; (b) backward mode.

\section{Conclusions}

In this work, a new CLTC multi-resonant DC-DC converter is proposed. Possessing the optimal ZVS + ZCS soft switching feature in all load range, CLTC benefits from little turn-off loss and high efficiency. The gain range is so wide that the demands of applications like battery chargers and DC microgrids can be satisfied easily. The problem of voltage regulation under light load conditions is so serious that voltage is not controllable. The hybrid full-bridge/half-bridge configuration is proposed to make gain curve monotonous under light load conditions. Discussion about voltage and current stresses, load and working frequency range in half-bridge configuration are put forth as well. Besides, a digital synchronous rectification strategy is proposed in forward mode to improve the working efficiency. The turn-on time of LVS switches is set to the same as the HVS switches. The conduction time of LVS switches equals the estimation value of body diodes' conduction time with the lightest load. Simulations verify the accuracy of this estimation. Furthermore, power loss analysis is conducted with different LVS DC voltages in two directions. Power loss is much more when the working frequency is beyond main resonant frequency, because of high conduction losses and turn-off losses. Efficiency with a half-bridge configuration is a little higher than that with full-bridge configuration in both directions, due to less turn-off losses. The loss is cut by $49 \%$ with the use of a synchronous strategy, showing 
the advantage in improving efficiency. At last, experiments are conducted to validate the theoretical analysis above. ZVS feature, the effectiveness of hybrid full-bridge/half-bridge configuration, and the validity of proposed digital synchronous rectification strategy are all verified through experiments. With the help of ZVS + ZCS feature, high efficiency can be harvested in a wide load range. The full load efficiency is $95.9 \%$ in forward mode and $94.9 \%$ in backward mode with LVS DC voltage of $50 \mathrm{~V}$. The maximum efficiency is $97.0 \%$ with a LVS DC voltage of $50 \mathrm{~V}$ and load of $2 \mathrm{~kW}$.

Acknowledgments: This research was supported by the National High Technology Research and Development Program (863 Program) of China (Grant: 2015AA050603). The authors would also like to thank the anonymous reviewers for their valuable comments and suggestions to improve the quality of the paper.

Author Contributions: Shu-huai Zhang, Yi-feng Wang, Bo Chen designed the main parts of the study, including hybrid full-bridge/half-bridge configuration, synchronous rectification strategy loss model, power loss analysis and experiments. Yi-feng Wang is also responsible for writing and revising the paper. Fu-qiang Han and Qing-cui Wang helped in the hardware development.

Conflicts of Interest: The authors declare no conflict of interest.

\section{References}

1. Fang, Z.; Wang, J.; Duan, S.; Shao, J.; Hu, G. Stability Analysis and Trigger Control of LLC Resonant Converter for a Wide Operational Range. Energies 2017, 10, 1448. [CrossRef]

2. Wang, C.; Li, W.; Wang, Y.; Han, F.; Meng, Z.; Li, G. An Isolated Three-Port Bidirectional DC-DC Converter with Enlarged ZVS Region for HESS Applications in DC Microgrids. Energies 2017, 10, 446. [CrossRef]

3. Wang, C.; Li, W.; Wang, Y.; Han, F.; Chen, B. A High-Efficiency Isolated LCLC Multi-Resonant Three-Port Bidirectional DC-DC Converter. Energies 2017, 10, 934. [CrossRef]

4. Chen, B.; Wang, P.; Wang, Y.; Li, W.; Han, F.; Zhang, S. Comparative Analysis and Optimization of Power Loss Based on the Isolated Series/Multi Resonant Three-Port Bidirectional DC-DC Converter. Energies 2017, 10, 1565. [CrossRef]

5. Twiname, R.P.; Thrimawithana, D.J.; Madawala, U.K.; Baguley, C.A. A New Resonant Bidirectional DC-DC Converter Topology. IEEE Trans. Power Electron. 2014, 29, 4733-4740. [CrossRef]

6. Wu, H.; Ding, S.; Sun, K.; Zhang, L.; Li, Y.; Xing, Y. Bidirectional Soft-Switching Series-Resonant Converter With Simple PWM Control and Load-Independent Voltage-Gain Characteristics for Energy Storage System in DC Microgrids. IEEE Trans. Power Electron. 2013, 28, 995-1007. [CrossRef]

7. Park, J.; Choi, S. Design and Control of a Bidirectional Resonant DC-DC Converter for Automotive Engine/Battery Hybrid Power Generators. IEEE Trans. Power Electron. 2014, 29, 3748-3757. [CrossRef]

8. Shen, Y.; Wang, H.; Al-Durra, A.; Qin, Z.; Blaabjerg, F. A Fixed-Frequency Bidirectional Resonant DC-DC Converter Suitable for Wide Voltage Gain Range. IEEE Trans. Power Electron. 2017, 99, 1-19.

9. Hu, S.; Deng, J.; Mi, C.; Zhang, M. Optimal design of line level control resonant converters in plug-in hybrid electric vehicle battery chargers. IET Electron. Syst. Transp. 2013, 4, 21-28. [CrossRef]

10. Tan, X.; Ruan, X. Equivalence relations of resonant tanks: A new perspective for selection and design of resonant converters. IEEE Trans. Ind. Electron. 2016, 63, 2111-2123. [CrossRef]

11. Corradini, L.; Seltzer, D.; Bloomquist, D.; Zane, R.; Maksimović, D.; Jacobson, B. Minimum Current Operation of Bidirectional Dual-Bridge Series Resonant DC/DC Converters. IEEE Trans. Power Electron. 2012, 27, 3266-3276. [CrossRef]

12. Ibanez, F.; Echeverria, J.; Vadillo, J.; Fontan, L. State-Plane Analysis of Anomalous Step-Up Behavior in Series-Resonant Converters. IEEE J. Emerg. Sel. Top. Power Electron. 2016, 4, 1026-1035. [CrossRef]

13. Li, X.; Bhat, A. Analysis and Design of High-Frequency Isolated Dual-Bridge Series Resonant DC/DC Converter. IEEE Trans. Power Electron. 2010, 25, 850-862.

14. Ibanez, F.; Echeverria, J.; Fontan, L. Novel technique for bidirectional series-resonant DC/DC converter in discontinuous mode. IET Power Electron. 2013, 6, 1019-1028. [CrossRef]

15. Ibanez, F.; Echeverria, J.; Vadillo, J.; Fontan, L. Frequency response analysis for bidirectional series resonant DC/DC converter in discontinuous mode. IET Power Electron. 2014, 7, 2374-2386. [CrossRef]

16. Ibanez, F.; Echeverria, J.; Vadillo, J.; Fontan, L. A Step-Up Bidirectional Series Resonant DC/DC Converter Using a Continuous Current Mode. IEEE Trans. Power Electron. 2015, 30, 1393-1402. [CrossRef] 
17. Jiang, T.; Zhang, J.; Wu, X.; Sheng, K.; Wang, Y. A Bidirectional Three-Level LLC Resonant Converter with PWAM Control. IEEE Trans. Power Electron. 2016, 31, 2213-2225. [CrossRef]

18. Jiang, T.; Zhang, J.; Wu, X.; Sheng, K.; Wang, Y. A Bidirectional LLC Resonant Converter with Automatic Forward and Backward Mode Transition. IEEE Trans. Power Electron. 2015, 30, 757-770. [CrossRef]

19. Jung, J.; Kim, H.; Ryu, M.; Baek, J. Design Methodology of Bidirectional CLLC Resonant Converter for High-Frequency Isolation of DC Distribution Systems. IEEE Trans. Power Electron. 2013, 28, 1741-1755. [CrossRef]

20. Zahid, Z.; Dalala, Z.; Chen, R.; Chen, B.; Lai, J. Design of Bidirectional DC-DC Resonant Converter for Vehicle-to-Grid (V2G) Applications. IEEE Trans. Transp. Electr. 2015, 1, 232-244. [CrossRef]

21. He, P.; Khaligh, A. Comprehensive Analyses and Comparison of $1 \mathrm{~kW}$ Isolated DC-DC Converters for Bidirectional EV Charging Systems. IEEE Trans. Transp. Electr. 2017, 3, 147-156. [CrossRef]

22. Lee, B.H.; Kim, M.Y.; Kim, C.E.; Park, K.-B.; Moon, G.W. Analysis of LLC resonant converter considering effects of parasitic components. In Proceedings of the INTELEC 31st International Telecommunications Energy Conference, Incheon, Korea, 18-22 October 2009; pp. 1-6.

23. Zhao, S.; Xu, J.; Trescases, O. Burst-Mode Resonant LLC Converter for an LED Luminaire With Integrated Visible Light Communication for Smart Buildings. IEEE Trans. Power Electron. 2014, 9, 4392-4402. [CrossRef]

24. Musavi, F.; Craciun, M.; Gautam, D.; Eberle, W. Control Strategies for Wide Output Voltage Range LLC Resonant DC-DC Converters in Battery Chargers. IEEE Trans. Veh. Technol. 2014, 63, 1117-1125. [CrossRef]

25. Cai, G.; Liu, D.; Liu, C.; Li, W.; Sun, J. A High-Frequency Isolation (HFI) Charging DC Port Combining a Front-End Three-Level Converter with a Back-End LLC Resonant Converter. Energies 2017, 10, 1462.

26. Kim, J.; Kim, C.; Kim, J.; Lee, J.; Moon, G. Analysis on Load-Adaptive Phase-Shift Control for High Efficiency Full-Bridge LLC Resonant Converter Under Light-Load Conditions. IEEE Trans. Power Electron. 2016, 31, 4942-4955.

27. Pan, H.; He, C.; Ajmal, F.; Chen, H.; Chen, G. Pulse-width modulation control strategy for high efficiency LLC resonant converter with light load applications. IET Power Electron. 2014, 7, 2887-2894. [CrossRef]

28. Wang, H.; Li, Z. A PWM LLC Type Resonant Converter Adapted to Wide Output Range in PEV Charging Applications. IEEE Trans. Power Electron. 2017, 1, 1-10. [CrossRef]

29. Kim, J.H.; Kim, C.E.; Kim, J.K.; Moon, G.W. Analysis for LLC resonant converter considering parasitic components at very light load condition. In Proceedings of the 8th International Conference on Power Electronics, Jeju, Korea, 30 May-3 June 2011; pp. 1863-1868.

30. Yeon, C.; Kim, J.; Park, M.; Lee, L.; Moon, G. Improving the Light-Load Regulation Capability of LLC Series Resonant Converter Using Impedance Analysis. IEEE Trans. Power Electron. 2017, 32, 7056-7067. [CrossRef]

31. Tsai, C.; Shen, C.; Su, J. A Power Supply System with ZVS and Current-Doubler Features for Hybrid Renewable Energy Conversion. Energies 2013, 6, 4859-4878. [CrossRef]

32. Xu, W.; Chan, N.; Or, S.; Ho, S.; Chan, K. A New Control Method for a Bi-Directional Phase-Shift-Controlled DC-DC Converter with an Extended Load Range. Energies 2017, 10, 1532. [CrossRef]

33. Joo, D.; Byun, J.; Lee, B.; Kim, J. Adaptive delay control for synchronous rectification phase-shifted full bridge converter with GaN HEMT. IEEE Trans. Power Electron. 2017, 53, 1541-1542. [CrossRef]

34. Yang, H.; Liao, J.; Cheng, X. Zero-voltage-transition auxiliary circuit with dual resonant tank for DC-DC converters with synchronous rectification. IET Trans. Power Electron. 2017, 6, 1157-1164. [CrossRef]

35. Fu, D.; Liu, Y.; Lee, F.; Xu, M. A Novel Driving Scheme for Synchronous Rectifiers in LLC Resonant Converters. IEEE Trans. Power Electron. 2009, 24, 1321-1329. [CrossRef]

36. Zhang, J.; Wang, J.; Zhang, G.; Qian, Z. A Hybrid Driving Scheme for Full-Bridge Synchronous Rectifier in LLC Resonant Converter. IEEE Trans. Power Electron. 2012, 27, 4549-4561. [CrossRef]

37. Duan, C.; Bai, H.; Guo, W.; Nie, Z. Design of a 2.5-kW 400/12-V High-Efficiency DC/DC Converter Using a Novel Synchronous Rectification Control for Electric Vehicles. IEEE Trans. Transp. Electr. 2015, 1, 106-114. [CrossRef]

(C) 2018 by the authors. Licensee MDPI, Basel, Switzerland. This article is an open access article distributed under the terms and conditions of the Creative Commons Attribution (CC BY) license (http:/ / creativecommons.org/licenses/by/4.0/). 